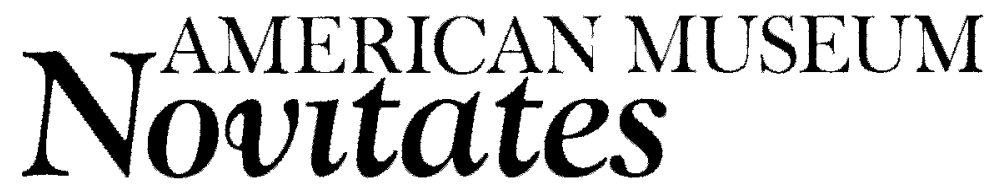

PUBLISHED BY THE AMERICAN MUSEUM OF NATURAL HISTORY CENTRAL PARK WEST AT 79TH STREET, NEW YORK, NY 10024 Number 3518, 32 pp., 74 figures

\title{
Revision of World Species of the Genus Nixonia Masner (Hymenoptera: Platygastroidea, Scelionidae)
}

\author{
NORMAN F. JOHNSON ${ }^{1}$ AND LUBOMÍR MASNER ${ }^{2}$
}

\begin{abstract}
The world fauna of the genus Nixonia is revised. The genus is described, its relationships with other scelionids are discussed, and a key to world species is presented. Nixonia pretiosa Masner (Namibia) and N. atra Masner (Angola, Democratic Republic of Congo, Kenya, Malawi, Rwanda, Zimbabwe) are redescribed, and 12 new species are described: $N$. bini, new species (Somalia), N. corrugata, new species (South Africa), N. elongata, new species (South Africa), $N$. flavocincta, new species (Namibia), N. gigas, new species (South Africa), N. krombeini, new species (India, Laos, Sri Lanka, Thailand, Vietnam), N. lamorali, new species (South Africa), N. pecki, new species (Botswana, South Africa, Zimbabwe), N. priesneri, new species (Egypt), N. sicaria, new species (Namibia), N. stygica, new species (South Africa), and N. watshami, new species (Botswana, Namibia, Zimbabwe). The only host record for the genus is for $N$. watshami, which been reared from the eggs of Acanthoplus discoidalis (Walker) (Orthoptera: Tettigoniidae, Hetrodinae) in Botswana and Namibia. The phylogenetic relationships among the species are discussed.
\end{abstract}

\section{INTRODUCTION}

The genus Nixonia Masner generally has been considered to represent the most plesiomorphic living genus of the family Scelionidae (Masner, 1958; Kozlov, 1970; Masner, 1976; Kozlov and Kononova, 1990). Until now, only two species were recognized: $N$. pretiosa Masner, described from Southwest Africa (Namibia), and $N$. atra Masner from Rhodesia (Zimbabwe). Both species were de- scribed on the basis of unique specimens. Subsequently, Masner (1976) indicated that he had studied additional African specimens from Egypt, Zaire, and South Africa, as well as Oriental specimens from India, Laos, and Vietnam (fig. 1). However, these species were not formally described.

The hosts for any species of Nixonia were unknown. All reared species of Scelionidae are egg parasitoids of spiders or of insects in the orders Odonata, Orthoptera, Mantodea,

\footnotetext{
${ }^{1}$ Department of Entomology, The Ohio State University, 1315 Kinnear Road, Columbus, OH 43212 (Johnson.2 @osu.edu).

${ }^{2}$ Agriculture and Agri-Food Canada, Research Branch, K. W. Neatby Building, Ottawa, Ontario K1A 0C6, Canada.
} 


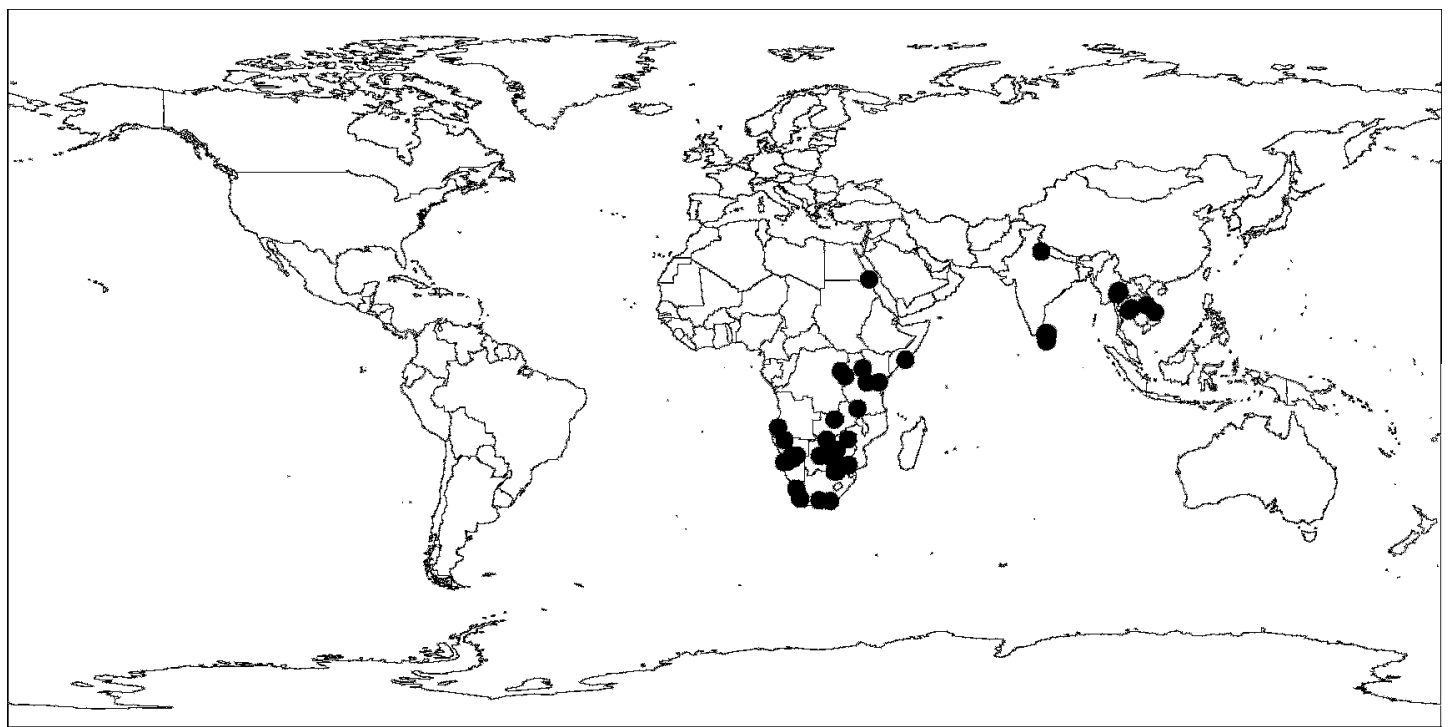

Fig. 1. Distribution of Nixonia Masner. Thirteen species are found in Africa; the only Asian species is $N$. krombeini, n.sp. Map drawn with units of latitude and longitude of equal size.

Embiidina, Hemiptera, Diptera, Coleoptera, Neuroptera, and Lepidoptera (Austin et al., 2005). It is generally believed that the plesiotypic host order for the family is Orthoptera because there are numerous host records from Tettigoniidae, Acrididae, and Gryllidae in several tribes of the generalized subfamily Scelioninae. However, until this time, the host of Nixonia had not been recorded in the scientific literature. One species, Nixonia watshami, has been reared from the eggs of armored bush crickets, Acanthoplus discoidalis (Walker) (Orthoptera: Tettigoniidae, Hetrodinae) in Namibia and Botswana (S. V. Green, personal commun.).

Our goal in this paper is to update and expand the generic description of Nixonia, formally describe all species that we have accumulated, provide an identification key for the species, and discuss the phylogeny of the genus and its position within the Scelionidae.

\section{MATERIALS}

This work is based on specimens in the following collections:

AEIC D. Wahl: American Entomological Institute, 30015 SW 56th Ave., Gainesville, FL, 32608-5047, USA
BMNH M. Fitton: The Natural History Museum, Cromwell Road, London SW7 5BD, England

BPBM A. S. Ramsdale: Bishop Museum, Honolulu, HI 96817-2704, USA

CASC W. Pulawski: California Academy of Sciences, Golden Gate Park, San Francisco, CA 94118, USA

CNCI A. Bennett: Canadian National Collection of Insects, Agriculture and Agri-Food Canada, K. W. Neatby Building, Ottawa K1A 0C6, Canada

IEAP G. Mineo: Istituto di Entomologia Agraria, Università di Palermo, Sicily, Italy

INHS D. Webb: Illinois Natural History Survey, Champaign, IL 61820, USA

ISNB J. Constant: Institut Royal des Sciences Naturelles de Belgique, Rue Vautier 29, B-1000 Bruxelles, Belgium

OSUC N. F. Johnson: The Ohio State University Insect Collection, 1315 Kinnear Road, Columbus, $\mathrm{OH}$ 43212, USA

SANC G. L. Prinsloo: South African National Collection of Insects, Plant Protection Research Institute, Pretoria, South Africa

UCDC S. Heydon: Bohart Museum of Entomology, University of California, Davis, USA 
USNM T. Nuhn: National Museum of Natural History, Washington, DC 20560, USA

Abbreviations and terms used in text: A1, A2, ... A14: antennomere $1,2, \ldots$ 14; claval formula: distribution of the large, multiporous basiconic sensilla on the underside of apical antennomeres of the female, with the segment interval specified followed by the number of sensilla per segment (Bin, 1981); IOS: interocular space, shortest distance between the inner margins of the compound eyes; LOL: lateral ocellar line, shortest distance between inner margins of median and lateral ocelli (Masner and Huggert, 1989); OOL: ocular ocellar line, shortest distance from inner orbit and outer margin of posterior ocellus (Masner and Huggert, 1989); POL: posterior ocellar line, shortest distance between inner margins of posterior ocelli (Masner and Huggert, 1989); epomial carina: the vertical portion of epomium on the pronotum; pronotal humeral carina: the horizontal portion of epomium on the pronotum; $\mathbf{S 1}, \mathbf{S 2}, \ldots$ S6: metasomatic sterna $1,2, \ldots 6$; $\mathbf{T 1}, \mathbf{T} 2, \ldots \mathbf{T} 7$ : metasomatic tergum 1, 2, ... 7. Under Material Examined, passages that are placed between square brackets are comments or interpretations of label data.

\section{NIXONIA MASNER}

Nixonia Masner, 1958: 101. Original description. Type: Nixonia pretiosa Masner, by monotypy and original designation. For subsequent taxonomic literature see Johnson (1992) or The Genera of Scelionidae (Hymenoptera: Platygastroidea) of the World (http://atbi.biosci.ohio-state.edu:210/ hymenoptera/eol_scelionidae.home).

Description: Medium to large, length 4.0$9.0 \mathrm{~mm}$, robust, cylindrical, moderately elongate (figs. 2, 3); predominantly black in color, sometimes with mesosoma ( $N$. pretiosa) or metasoma ( $N$. corrugata, $N$. pecki) reddish in part, or with yellow markings ( $N$. flavocincta); body with coarse surface sculpture and matte microsculpture; macropterous; with relatively low degree of secondary sexual dimorphism.

Head subglobose, moderately transverse when viewed dorsally (fig. 3); vertex rounded, hyperoccipital carina absent; occipital carina variably developed; lateral ocellus close to or contiguous with inner orbit of compound eye; compound eye large, bare; frons convex, without frontal depression, median longitudinal carina absent; head without raised interantennal process between toruli; torulus opening anteriorly; submedian carina absent; orbital carina absent; lower frons without fanlike striae; interocular space variable in width (figs. 7, 12, 13); inner orbits weakly to strongly divergent ventrally; clypeus short, broadly transverse, flat to weakly depressed, postclypeus and anteclypeus differentiated in some species by change in sculpture: anteclypeus smooth; malar sulcus absent; gena broadly rounded, convex; labrum sometimes partly exposed; mandible usually broad, usually bidentate (figs. 10,11, unidentate in $N$. bini), teeth transversely oriented; maxillary palpus 5-segmented; labial palpus 2-segmented; antenna 14-merous in both sexes; radicle inserted apically into A1, more or less parallel to longitudinal axis of $\mathrm{A} 1$; without expanded apical clava in female; gustatory sensilla on female antenna arranged in transverse pairs on apical antennomeres; claval formula A5-A14/ 2-2-2-2-2-2-2-2-2-2; male antenna with tyloid on A4-A5, sometimes on A6-7, rarely with rudiment on A8.

Mesosoma cylindrical (figs. 2, 3), in dorsal view longer than wide, in lateral view deep, somewhat flattened dorsally; pronotum in dorsal view strongly developed laterally, anterolateral corners rounded; transverse pronotal carina absent; epomial carina absent; pronotal humeral carina absent; anterior face of pronotum with pair of deep transverse pilose grooves near anterior margin, these often accumulate white exudate (e.g., fig. 35); lateral face of pronotum largely convex, without scrobe for reception of foreleg; netrion very broad, as wide as tegula, fusiform, open ventrally; anterior margin of mesoscutum meeting pronotum dorsally; mesoscutum semioval in outline; parapsidal lines often present; notauli absent; skaphion absent; transscutal articulation well developed, simple, not crenulate; scutellum semicircular in outline to slightly wider than long, unarmed, convex, sometimes with weak medial depression; axilla well developed; metanotum narrow, dorsellum weakly differentiated, un- 


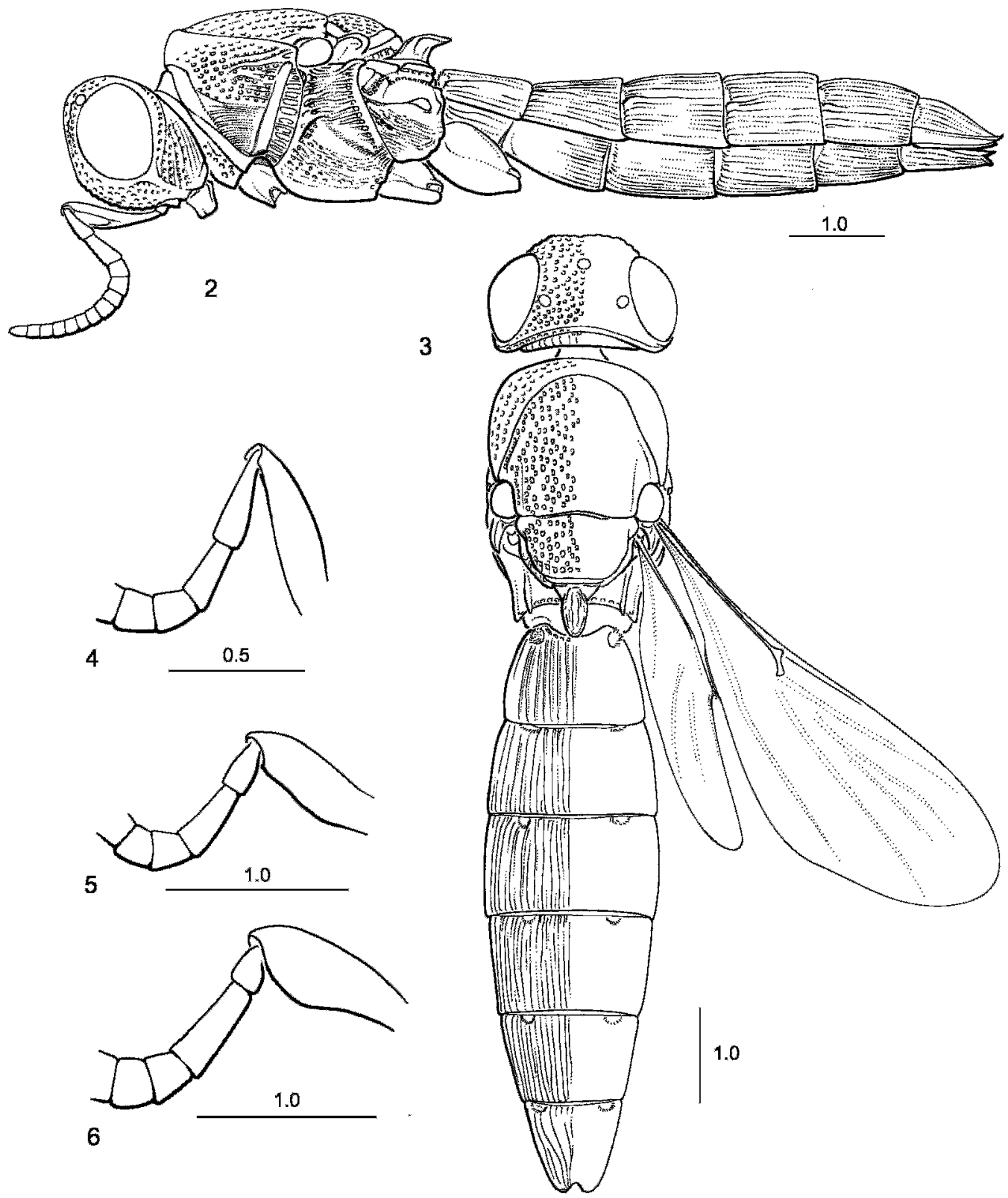

Figs. 2-6. 2. Nixonia pecki, n.sp., lateral habitus (OSUC 146419). 3. N. pecki, dorsal habitus (OSUC 146419). 4. N. flavocincta, n.sp., antennomeres 1-5 (OSUC 146461). 5. N. krombeini, n.sp., antennomeres 15 (OSUC 146436). 6. N. atra Masner, antennomeres 1-5 (OSUC 146405).

armed; dorsal surface of propodeum with dense, fine pilosity; median keels of propodeum raised and fused to form a single strong medial tooth, tooth varying in shape from pointed to ligulate or cordate, apex of tooth turned downward and pointing posteriorly, parallel to longitudinal axis of body; lateral plicae on propodeum strong; posterior face of propodeum smooth, glabrous; foramen of propodeum subcircular in cross-section, open- 


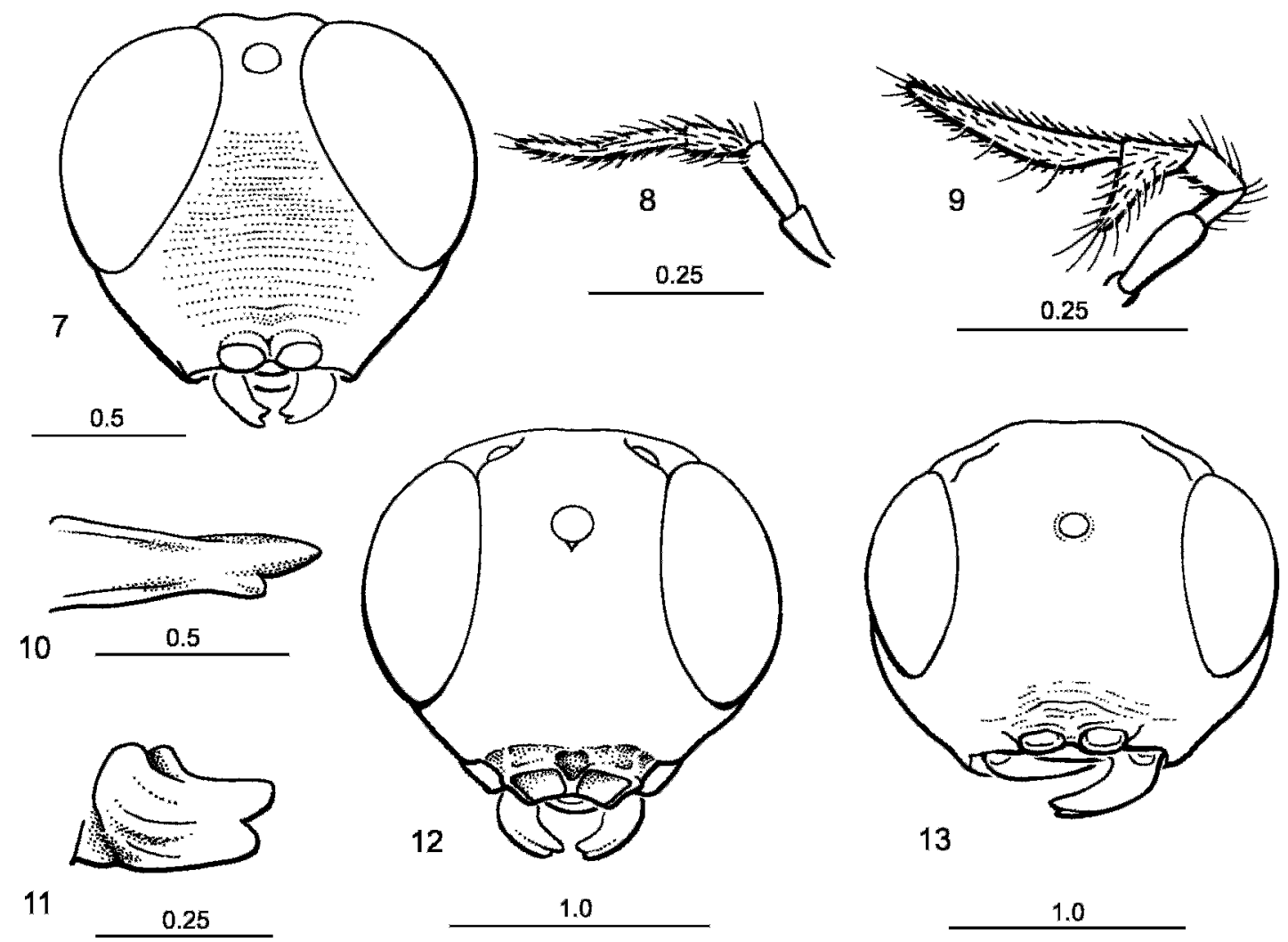

Figs. 7-13. 7. Nixonia flavocincta, n.sp., head, frontal view (OSUC 146461); 8. N. atra Masner, maxillary palpomeres 2-5 (OSUC 146405). 9. $N$. watshami, n.sp., maxillary palpomeres 1-5 (OSUC 146418). 10. $N$. atra, mandible (OSUC 146405). 11. N. krombeini, n.sp., mandible (OSUC 146436). 12. N. krombeini, head, frontal view (OSUC 146436). 13. $N$. watshami, head, frontal view (OSUC 146418).

ing on and occupying ventral half of posterior surface of propodeum; mesopleuron very large, prominent; mesopleural depression well developed: broad, deep; mesopleural carina absent; sternaulus absent; mesopleural pit absent; anterior margin of ventral portion of mesepisternum straight, not protruding between forecoxae; mesepisternum and mesepimeron separated by line of well-developed foveae; episternal foveae absent; dorsal corner of mesepimeron produced into strong, acute tooth directed posteriorly; anteroventral portion of metapleuron rounded, not separated from lateral face by carina; metapleural pit absent; posterior margin of metapleuron not produced; metapleuron separated from propodeum dorsally and posteriorly by deep, sigmoid groove; posterolateral corners of propodeum not projecting posteriorly; legs relatively short, strong; posterior surface of hind coxa with fine transverse striae; femora not incrassate; trochantellus present on all legs; outer surface of tibia with fine to strong spines; tibial spur formula 1-2-2, outer spur shorter than inner on mid-, hindleg; hind tibia with two longitudinal fine keels; tarsal formula 5-5-5; tarsomeres tapering in width apically; hind tarsus laterally compressed, higher than wide; hind basitarsus keeled ventrally and laterally, diamond-shaped in cross-section; pretarsal claws simple; forewing not extending to apex of T6, moderately to strongly infuscate, marginal cilia very short; $\mathrm{R}$ straight, extending through basal 0.4 of length of forewing, clearly forked apically, without large bristles; $\mathrm{R}_{1}$ short, not reaching costal 
margin, therefore without true marginal vein, costal margin of forewing usually folded longitudinally to give impression that $R_{1}$ reaches wing margin; r-rs (stigmal vein) longer than $\mathrm{R}_{1}$, slightly turned downward apically; no other tracheate veins in forewing; apical portion of forewing with six pigmented, convex longitudinal folds in position of $\mathrm{R}$, $\mathrm{M}, \mathrm{Cu}$; hindwing with $\mathrm{R}$ tracheate at least in its basal half, never reaching hamuli and costal margin; no bristles on R; three hamuli present; cilia on posterior margin of hindwing longer than marginal cilia of forewing.

Metasoma (figs. 2, 3) cylindrical, slightly to distinctly longer than head and mesosoma combined; all segments, except apical segment in male, subequal in length, first segment slightly the longest; female with six terga and sterna visible externally, male with seven terga and sterna visible; male T7 much shorter than preceding segment, apically rounded, reflexed to almost vertical orientation; submarginal ridge well developed, defined by narrow laterotergites, laterosternites absent; no spiracles visible; anterolateral corners of terga with finely pilose "collecting area"; female T6 apically emarginate, without median raised field of microsetae or secretion; S1 flat, not laterally compressed, not extending anteriorly between hind coxae, anterolateral corner with finely pilose "collecting area"; anterior margin of S2 straight; felt fields on sterna lacking.

DiAgnosis: Nixonia is superficially similar to many genera in the tribe Scelionini, particularly Scelio Latreille, and to the large, elongate species of the genera Macroteleia Westwood and Triteleia Kieffer. From all of these it is easily distinguished by the 14merous, nonclavate antennae; the strong medial propodeal tooth; and the presence of two tibial spurs on both the mid- and hind tibiae.

Geographic Distribution: The greatest concentration of species of Nixonia is found in southern Africa, but within that continent the genus ranges north to Egypt, Kenya, Somalia, Rwanda, and the Democratic Republic of Congo (former Zaire). A single species, N. krombeini, is found in in Sri Lanka, northern India, and Southeast Asia (Thailand, Laos, and Vietnam).
Biology: Only one species has been reared: Nixonia watshami, n.sp. parasitizes the eggs of Acanthoplus discoidalis (Orthoptera: Tettigoniidae, Hetrodinae). The subfamily Hetrodinae is endemic to Africa and adjacent areas of the Arabian Peninsula (Otte et al., 2005). Hence, the host of at least $N$. krombeini in tropical Asia must be some other large orthopteran.

RELATIONSHIPS: The discussions of the relationships of the genus Nixonia that appear in the published literature are fairly superficial. The primary concern of authors has been to differentiate Nixonia from other genera, rather than to analyze its position within the family. Diagnosis is a task easily accomplished as it is the only living platygastroid with 14-merous antennae and is one of the few with a tibial spur formula of 1-2-2. These are, however, plesiomorphic characters. The monophyly of the genus is strongly supported by the arrangement of multiporous basiconic sensilla on the female antenna. These occur in transverse pairs on the apical antennomeres (figs. 29, 44, 72), rather than the typical longitudinal orientation in all other platygastroids. Additional characters supporting monophyly are the presence of a median propodeal tooth, the absence of a malar carina, and the longitudinal tibial carinae.

Previous authors have generally considered Nixonia as the most plesiomorphic of the living scelionids (Masner, 1958; Kozlov, 1970; Masner, 1976; Kozlov and Kononova, 1990), implicitly placing it as the sister group of all other extant members of the family. The Eocene fossil genus Archaeoscelio lacks laterotergites on the metasoma, a characteristic of all other described platygastroids, including Nixonia. Archaeoscelio is also significant because of its 14-merous antennae. Thus, some basal rearrangement of the intuitive scelionid phylogeny soon may be warranted. Austin and Field (1997) depicted Nixoniini as one branch in the basal polytomy of 19 clades for the Scelionidae. Although their cladogram is only one possible resolution-it is not a consensus tree of all cladograms discovered-it suggests that Scelionidae is not a monophyletic family: two genera of the tribe Sparasionini cluster with the family Platygastridae. Thus, the 
hypothesis that Nixonia is the sister group to all other scelionids is open to question.

Determination of the closest relative of Nixonia is impossible at this time. The Australian endemic genus Neoscelio Dodd also has the upper posterior corner of the mesepimeron produced backward, but the value of this character has not been tested in a comprehensive analysis. The truncated $\mathrm{R}$ in the hindwing is shared with the tribe Scelionini. All of the species of this tribe, as far as is presently known, parasitize the eggs of Acrididae deposited in the soil. Similarly, the one known host record for Nixonia is also an orthopteran that deposits egg masses in the soil.

Notes: Masner (1976) stated that specimens of Nixonia are the largest known scelionids. With further collecting, we must correct this. The largest Nixonia, $N$. gigas, is $9.0 \mathrm{~mm}$ in length, but this is exceeded by some undescribed species of Triteleia.

\section{KEY TO SPECIES OF NIXONIA}

1 A2 longer than A3 (fig. 4)..................2

- A3 longer than A2 (figs. 5, 6)............5

2. Femora and tibiae yellow (figs. 32, 60); eye height at least 2.5 times IOS (figs. 7,

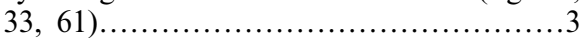

- Femora and tibiae reddish brown to black (figs. 24, 64); eye height less than 2 times IOS (figs. 25, 65)..................... 4

3. Medial portion of posterior margin of pronotum, scutellar rim, tegulae, propodeal tooth, margins of T1-T4, tarsi yellow (figs. 32, 34); upper mesepisternum punctate (fig. 32); Namibia..

\section{N. flavocincta, n.sp.}

- Mesosoma, metasoma black without yellow markings, tarsi dark brown (figs. 60, 62); upper mesepisternum longitudinally striate (figs. 60); Namibia.

N. sicaria, n.sp.

4. Forewings extending at most only to middle of T4 (fig. 24); female metasoma with T2-T4 brick red, mid- and hind femora and tibiae reddish brown; South Africa.................. N. corrugata, n.sp.

- Forewings longer, extending nearly to posterior margin of T5 (fig. 64); female body and legs entirely black; South Africa........................ N. stygica, n.sp.
5. A3 only slightly longer than A2 (fig. 5), length of A3 1.15 times length of

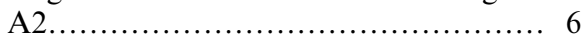

- A3 significantly longer than A2 (fig. 6), length of A3 1.4-3.1 times length of A2 .................................... 7

6. Occipital carina not developed (fig. 30); female T6 irregularly carinate; female body and legs entirely black; South Africa....................... elongata, n.sp.

- Occipital carina massive (figs. 3, 54); female T6 longitudinally carinate; female metasomatic segments $2-5$ brick red; legs, except coxae, reddish orange; South Africa, Botswana........... N. pecki, n.sp

7. Maxillary palpomere 4 cylindrical (fig. 8); mandible long, with lower tooth either absent or much shorter than upper (fig. 10), base of mandible with dense tuft of thick setae (figs. 22, 51)..........8

- Maxillary palpomere 4 with strongly expanded lateral lobe, width of palpomere nearly equal to its length (figs. 9, 73); mandible short, bidentate, lower tooth only slightly shorter than upper (fig. 11), base of mandible without dense tuft of thick setae............................... 10

8. Mandible unidentate, with no indication of lower tooth (fig. 22); legs orangeyellow; Somalia................... bini, n.sp.

- Mandible with short, but distinct lower tooth (fig. 10); legs black..................9

9. Mesoscutum and scutellum with irregular, sharply defined rugulosities, with small setigerous punctures scattered over surface (fig. 50); tegula reddish brown, distinctly lighter in color than mesoscutum; Egypt.................... N. priesneri, n.sp.

- Mesoscutum and scutellum covered by deep, confluent, large setigerous punctures (fig. 16); tegula black, concolorous with mesoscutum; Angola, Congo, Kenya, Malawi, Rwanda, Zimbabwe...

\section{N. atra Masner}

10. Fore- and midtibiae with numerous stout, semierect, dark spines over outer surface (fig. 41); propodeal tooth cordate, longitudinally carinate (fig. 40); scutellum longitudinally striate; female T6 deeply, narrowly emarginate posteromedially (fig. 39); large, $9 \mathrm{~mm}$ in length; South Africa.

$$
\text { N. gigas, n.sp. }
$$

- Fore and midtibiae at most with small, semiapressed spines; propodeal tooth parallel-sided and pointed or ligulate, usually with deep medial depression; scutellum areolate-punctate; female T6 with only 
shallow emargination posteromedially; moderate in size, 5-7 $\mathrm{mm}$ in length......11

11. Eye height distinctly larger than IOS (figs. 12, 43); mesoscutum with scattered punctures and wide interstices with dense mat microsculpture (fig. 44); India, Laos, Sri Lanka, Thailand, Vietnam........ N. krombeini, n.sp.

- Eye height subequal to or only slightly larger than IOS (figs. 13, 47, 57, 69); mesoscutum with dense large punctures and narrow interstices with shining surface; Africa........................ 12

12. IOS 0.9 times eye height (fig. 47); forewing with several streaks of heavy infuscation; body length $7 \mathrm{~mm}$; South Africa.................... N. lamorali, n.sp.

- IOS equal to eye height (figs. 57, 69) forewing with only moderate streaks of infuscation; body length $5.0-5.5 \mathrm{~mm} . .13$

13. Mesosoma, antennae, and legs entirely dark brown to black (figs. 68, 70); Botswana, Namibia, Zimbabwe. ....................... N. watshami, n.sp.

- Pronotum, mesonotum, antennomeres 13 , and legs beyond coxae deep orange to reddish brown (figs. 56, 58); Namibia......

..N. pretiosa Masner

Nixonia atra Masner

Figures 6, 8, 10, 13-17

Nixonia atra Masner, 1970: 90. Original description. Masner, 1976: 12 (type information).

DesCriPtion: Holotype male. Length: 6.9 $\mathrm{mm}$; body generally black; femora, tibiae, tarsi, antenna, tegula black; palpi yellowish brown; wings infuscate throughout, brownish.

Head (figs. 13-16) transverse in dorsal view, width 2.0 times length; vertex rugulose-punctate, shining; OOL short, lateral ocellus separated from inner orbit by less than 1 ocellar diameter; POL 1.4 times LOL; occiput rugulose-punctate, shining; occipital carina not developed; frons (fig. 15) rugulose-punctate, shining, above toruli with few transverse wrinkles medially; frons broad, IOS 1.1 times greatest length of eye; toruli separated by distance of approximately one-half diameter of torulus, frons between toruli not projecting, flat; rim of torulus raised dorsally and medially; apical margin of clypeus straight; area below eye (in normal position of malar sulcus) with fine granular microsculpture; cheeks laterad of malar area coarsely punctate, without longitudinal sculpture; mandible elongate, bidentate, upper tooth significantly longer than lower, with dense tuft of long, coarse setae at base (fig. 15); maxillary palpal segment 4 cylindrical (fig. 8); A1 finely punctate, greatest width in apical two-thirds of segment; length of A3 1.9 times of A2.

Mesosoma (figs. 14, 16) height 1.1 times width, length 1.4 times height; pronotal shoulders rugose-punctate; lateral surface of pronotum finely punctate; netrion with deep punctures only; mesoscutum deeply punctate, with fine reticulate microsculpture; parapsidal lines absent; scutellum coarsely punctate, with reticulate microsculpture, without longitudinal sculpture; median propodeal tooth moderately wide, two times as long as wide, pointed apically, rugulose; upper mesepisternum largely smooth, with only weakly indicated longitudinal rugulae; line of fine foveae separating mesepisternum and mesepimeron extending from base of wing to coxal cavity; lower mesepisternum coarsely reticulate-punctate; mesepimeral hook longitudinally keeled; tegula with fine transverse striae; $\mathrm{R}_{1}$ in forewing distinctly separated from costal margin, extending only halfway from $\mathrm{R}$ to margin; forewing surpassing apex of T5; $\mathrm{R}$ in hindwing with tracheate section short, broadly separated from hamuli by distance greater than its length; tibiae with fine, semidecumbent spines on outer surface.

Metasoma (fig. 16) 2.3 times longer than its greatest width; T1 distinctly wider than long; all terga longitudinally rugose.

Additional characters from female: T6 with relatively broad emargination medially, width of emargination greater than depth; base of T6 with anteromedial field of granulate microsculpture.

Diagnosis: Most similar to $N$. bini and $N$. priesneri, distinguished by its bidentate mandibles (unidentate in $N$. bini) and the absence of transverse sculpture on the mesoscutum.

Material ExAmined: Holotype male: "RHODESIA, Victoria Falls, Nat'l Park, IV-3-6-1968, Paul Spangler; Nixonia atra 


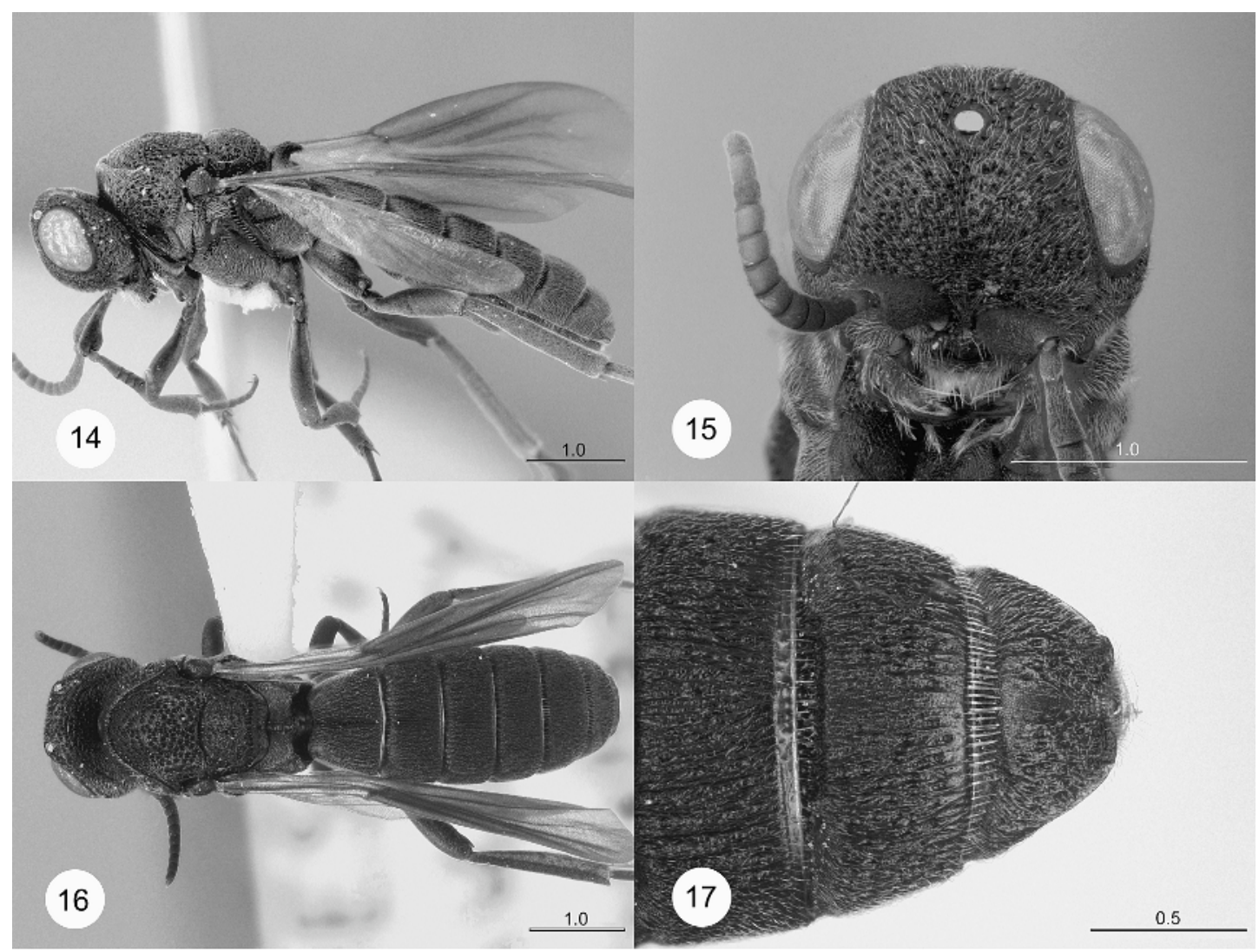

Figs. 14-17. Nixonia atra Masner. 14. Lateral habitus (OSUC 146402). 15. Head, frontal view (OSUC 146402). 16. Dorsal habitus (OSUC 146402). 17. Apex of metasoma, dorsal view (OSUC 146403). Scale in millimeters.

Masner ô HOLOTYPE; Type No, 70765, U.S.N.M." Deposited in USNM.

Other material (10 specimens): ANGOLA: $15 \mathrm{mi} \mathrm{N}$ Lubango [Sá da Bandeira on label], $\sim 6500 \mathrm{ft}$ [1980 m], Prov. da Huila, 3.III.1972, 1 male, OSUC 146407. DEMOCRATIC REPUBLIC OF CONGO: Cp. Rwuindi, Parc National Albert, 1000 m, 25.IV.1936, L. Lippens, 1 male, OSUC 149429. KENYA: Maungu, 2000', 1.V.1976, I. Bampton, 1 male, OSUC 149515. Kisumu, Nyanza Prov., 1937, C. B. Symes, airplane, 1 male, OSUC 146408. MALAWI: Chitipa District, Jembya Reserve, $13 \mathrm{~km}$ SSE Chisanga, $10^{\circ} 08^{\prime} \mathrm{S} \quad 33^{\circ} 27^{\prime} \mathrm{E}$, 1870 m, 11-20.I.1989, J. Rawlins, S. Thompson, 1 female, OSUC 146406. RWANDA: Bitshumbi, Parc National Albert, SL Edouard, 925 m, 15.IV.1936, L. Lippens, 1 male, OSUC 149428. ZIMBABWE: Harare [Sa- lisbury, Rhodesia on label], I.1979, A. Watsham, 1 male, OSUC 146402; XIXII.1981, pan trap, 3 females, OSUC 146403, OSUC 146404, OSUC 146405. Deposited in AEIC, BMNH, CNCI, IEAP, ISNB.

Nixonia bini, new species Figures 18-23

DesCRIPTION: Holotype female: Length: $6.6 \mathrm{~mm}$; body generally black; femora, tibiae, tarsi, tegula reddish brown; A1-A3 reddish brown, antenna otherwise dark brown to black; palpi yellowish; wings partially infuscate, brownish.

Head (figs. 18-20) moderately transverse in dorsal view, width 1.4 times length; vertex rugulose-punctate, shining; OOL short, lateral 


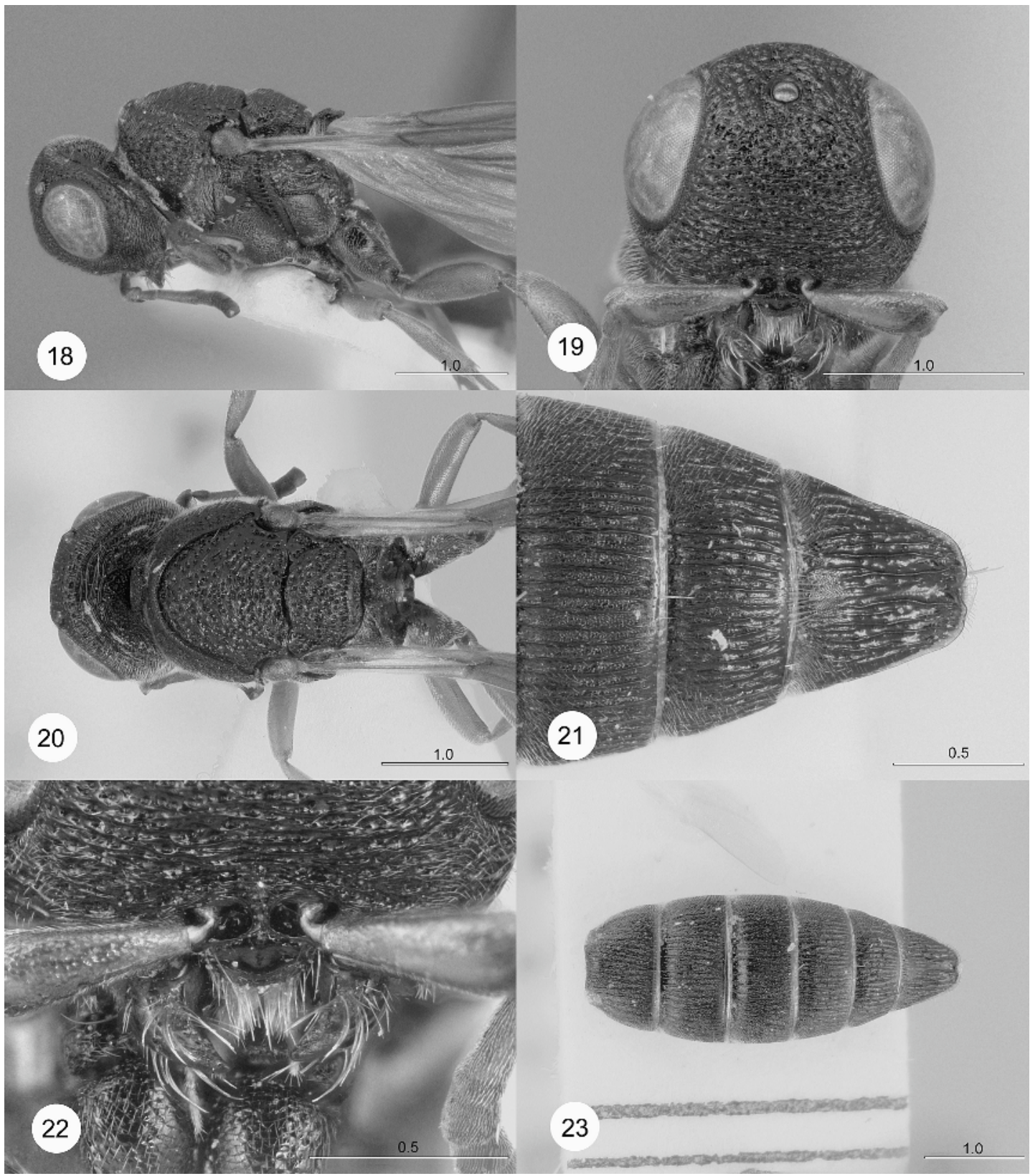

Figs. 18-23. Nixonia bini, n.sp., holotype female (OSUC 146410). 18. Head and mesosoma, lateral view (image reversed). 19. Head, frontal view. 20. Head and mesosoma, lateral view. 21. Apex of metasoma, dorsal view. 22. Lower head and mouthparts, frontal view. 23. Metasoma, dorsal view. Scale in millimeters.

ocellus separated from inner orbit by less than 1 ocellar diameter; POL 1.6 times LOL; occiput punctate, shining, with well-developed transverse arcuate rugulae; occipital carina present medially, obscured amid numerous transverse rugulae; frons rugulose-punctate, shining, above toruli with dense transverse wrinkles; frons (fig. 19) fairly broad, IOS equal to greatest length of eye; toruli separated by distance of approximately one-half 
diameter of torulus; frons between toruli not projecting, flat; rim of torulus raised dorsally; apical margin of clypeus straight; malar region rugose-punctate, without microsculpture in position typical of malar sulcus; cheeks rugose-punctate, with distinct longitudinal sculpture; mandible (fig. 22) elongate, unidentate, with dense tuft of long, coarse setae at base of mandible; maxillary palpal segment 4 cylindrical; A1 finely reticulate, greatest width in apical two-thirds of segment; length of A3 1.7 times of $\mathrm{A} 2$.

Mesosoma (figs. 18, 20) height 1.1 times width, length 1.3 times height; pronotal shoulders rugose-punctate; lateral surface of pronotum coarsely punctate; netrion with deep punctures only; mesoscutum rugosepunctate, with distinct transverse sculpture posteriorly, shining; parapsidal lines present; scutellum rugose-punctate, with fine longitudinal elements in posterior half; median propodeal tooth only slightly longer than wide, apically rounded, rugulose; upper mesepisternum with strong longitudinal sculpture; mesepisternum and mesepimeron separated by line of fine foveae extending from base of wing to coxal cavity; lower mesepisternum finely reticulate-punctate; mesepimeral hook longitudinally keeled; tegula with granular microsculpture; $\mathrm{R}_{1}$ in forewing distinctly separated from costal margin, extending less than halfway from $\mathrm{R}$ to margin; apex of forewing slightly surpassing apex of T4; $\mathrm{R}$ in hindwing with tracheate section short, broadly separated from hamuli by distance greater than its length; tibiae with fine, semidecumbent spines on outer surface.

Metasoma (figs. 21, 23) 2.5 times longer than greatest width; T1 distinctly wider than long; terga longitudinally rugose; T6 with relatively narrow emargination medially, width of emargination greater than depth; base of T6 with anteromedial field of granulate microsculpture.

Diagnosis: Most similar to N. atra and N. priesneri, distinguished by the unidentate mandible.

ETYMOLOGY: Named in honor of our friend and colleague, Dr. Ferdinando Bin (Università di Perugia), collector of the unique specimen, and innovator in the study of scelionid structure and behavior.
Material Examined: Holotype female: SOMALIA: Mogadiscio, Afgoi-Shabelli Valley, 1-15.ii.1977, F. Bin, malaise, OSUC 146410, deposited in CNCI.

\section{Nixonia corrugata, new species}

Figures 24-27

Description: Holotype female. Length: $5.6 \mathrm{~mm}$; head, mesosoma, base of T1, T5-T6 black, apex of T1, T2-T4 dark red; fore-, midfemora largely black, hind femur dark red; tibiae, tarsi, antenna entirely black; tegula dark brown; palpi brown; wings partially infuscate, brownish.

Head (figs. 24-26) moderately transverse in dorsal view, width 1.5 times length; vertex rugulose-punctate, shining; OOL short, lateral ocellus separated from inner orbit by less than 1 ocellar diameter; POL 1.3 times LOL; occiput rugulose-punctate, shining; occipital carina present medially as low, crenulate carina; frons transversely rugose, shining, transverse rugae widely spaced, strong; frons (fig. 25) narrow, IOS 0.8 times greatest length of eye; toruli separated by distance of approximately one-half diameter of torulus; frons between toruli not projecting anteriorly, flat; rim of torulus raised dorsally, laterally, medially; apical margin of clypeus broadly convex; area below eye (in normal position of malar sulcus) with fine granulate microsculpture; cheeks laterad of malar area transversely to longitudinally rugulose; mandible short, bidentate, upper tooth only slightly longer than lower, without dense basal tuft of setae; maxillary palpal segment 4 distinctly expanded medially, subtriangular; A1 finely reticulate, greatest width at midpoint of segment; length of A3 0.6 times length of A2.

Mesosoma (figs. 24, 26) as high as wide, length 1.6 times height; pronotal shoulders rugose-punctate; lateral surface of pronotum with fine longitudinal rugulosity; netrion punctate-rugulose, with strong longitudinal sculpture; mesoscutum deeply punctate, with fine granular microsculpture, weak transverse rugulae posteriorly; parapsidal lines present; scutellum rugose-punctate, with fine longitudinal elements in posterior half; median propodeal tooth rhomboidal, length 1.5 times greatest width, rounded apically, rugulose; 


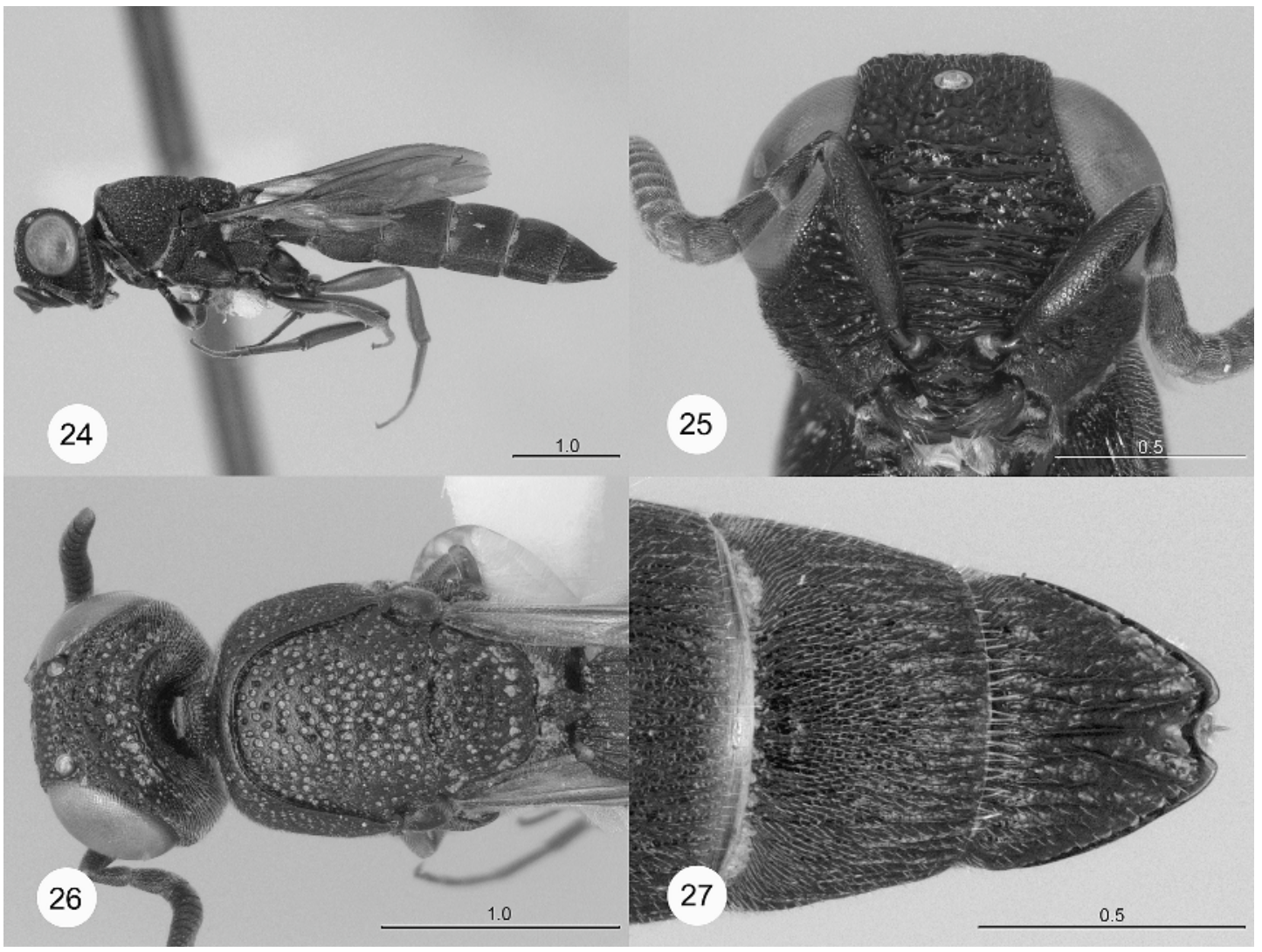

Figs. 24-27. Nixonia corrugata, n.sp., holotype female (OSUC 146424). 24. Lateral habitus. 25. Head, frontal view. 26. Head and mesosoma, dorsal view. 27. Apex of metasoma, dorsal view. Scale in millimeters.

upper mesepisternum finely longitudinally punctate-rugose; fine foveae separating mesepisternum and mesepimeron extending from base of wing to coxal cavity; lower mesepisternum finely reticulate-punctate; mesepimeral hook longitudinally keeled; tegula finely punctate; apex of $\mathrm{R}_{1}$ reaching costal margin; apex of forewing only reaching midpoint of $\mathrm{T} 4 ; \mathrm{R}$ in hindwing with tracheate section short, broadly separated from hamuli by distance greater than its length; tibiae with fine, semidecumbent spines on outer surface.

Metasoma (fig. 27) 3.5 times longer than greatest width; T1 distinctly wider than long; T1-T3, T6 longitudinally rugose, sculpture effaced medially on T4-T5; female T6 with large, wide, semioval, apical emargina- tion, width greater than depth; T6 anteromedially without distinctive field of microsculpture.

Diagnosis: Distinguished from the only other species with red metasoma, N. pecki, n.sp., by the short third antennomere and coarsely transverse sculpture on the frons.

ETYMOLOGY: The specific epithet corrugata refers to the strong transverse wrinkles on the frons.

Material Examined: Holotype female: SOUTH AFRICA: Western Cape Prov., The Baths S. of Citrusdale [sic], $32^{\circ} 44.044^{\prime} \mathrm{S}$ $19^{\circ} 02.336^{\prime} \mathrm{E}, \quad 12-14 . i 1.2002$, J. George, J. Kim, yellow pan trap, OSUC 146424, deposited in CNCI. Paratypes: 3 males with same data as holotype (OSUC 146425146427), deposited in CNCI, SANC. 


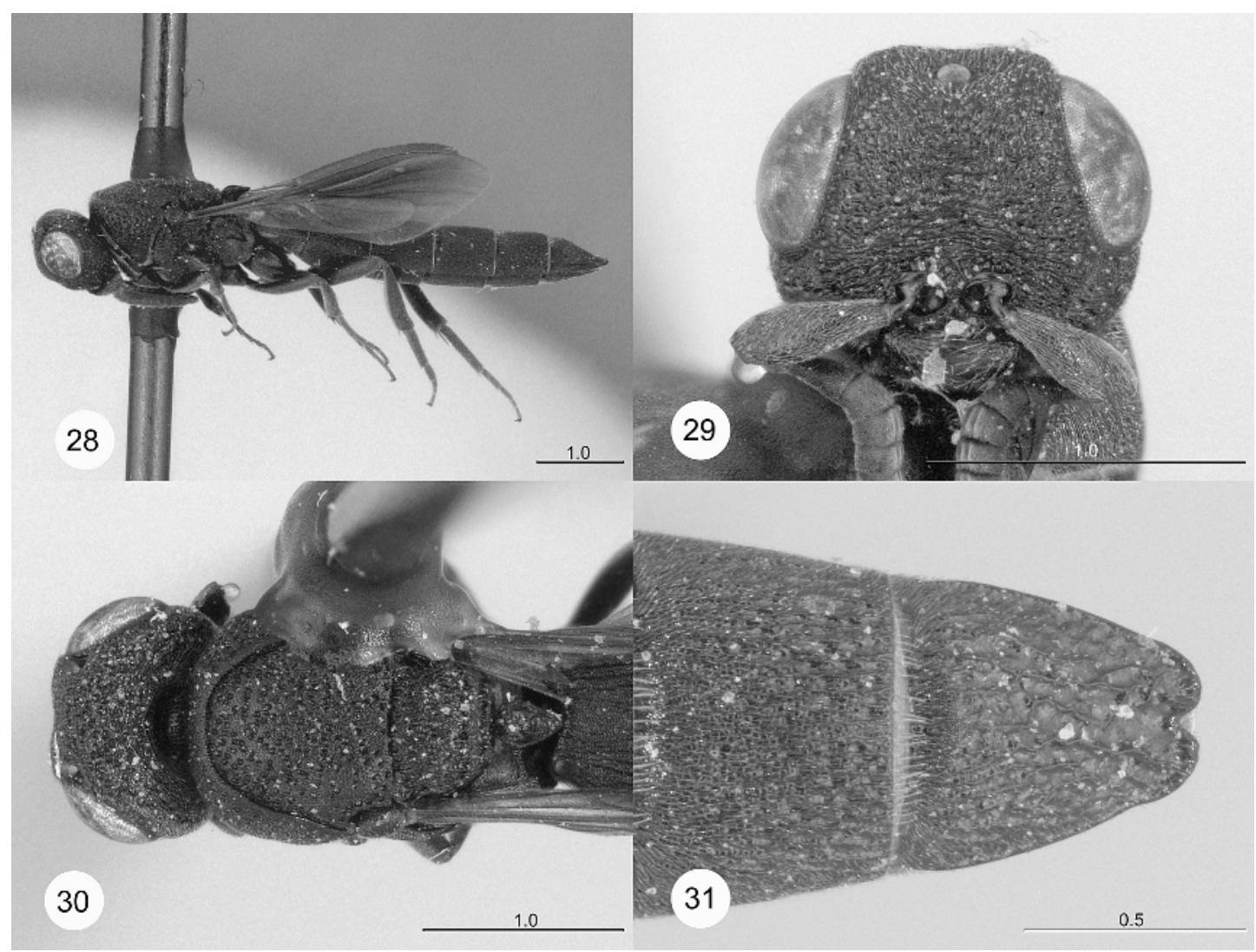

Figs. 28-31. Nixonia elongata, n.sp., holotype female (OSUC 146411). 28 Lateral habitus. 29. Head, frontal view. 30. Head and mesosoma, dorsal view. 31. Apex of metasoma, dorsal view. Scale in millimeters.

Nixonia elongata, new species Figures 28-31

Description: Holotype female. Length: $6.7 \mathrm{~mm}$; body generally black; femora, tibiae, tarsi, antenna, tegula black; palpi light brown; wings infuscate throughout, brownish.

Head (figs. 28-30) moderately transverse in dorsal view, width 1.6 times length; vertex rugulose-punctate, shining; OOL short, lateral ocellus separated from inner orbit by less than one ocellar diameter; POL 1.6 times LOL; occiput rugulose-punctate, shining; occipital carina present medially as low, crenulate carina; frons (fig. 29) rugulose-punctate, shining, above toruli with dense transverse wrinkles; frons broad, IOS 1.1 times greatest length of eye; toruli closely approximated, separated by distance less than one-half torulus diameter; frons between toruli not projecting, flat; rim of torulus raised dorsally; apical margin of clypeus straight; area below eye (in normal position of malar sulcus) with fine granulate microsculpture; cheeks laterad of malar area rugosepunctate, with fine longitudinal elements; mandible short, bidentate, upper tooth only slightly longer than lower, without dense basal tuft of setae; maxillary palpal segment 4 distinctly expanded medially, subtriangular; A1 finely reticulate, greatest width in apical two-thirds of segment; length of A3 1.2 times length of A2.

Mesosoma (figs. 28, 30) as high as wide, length 1.5 times height; pronotal shoulders coarsely punctate; lateral surface of pronotum coarsely punctate; netrion with weak longitudinal sculpture, deep punctures; mesoscutum deeply punctate, with fine reticulate microsculpture; parapsidal lines present; scutellum coarsely punctate, with reticulate microsculpture, without longitudinal sculpture; median 
propodeal tooth rhomboidal, length 1.5 times greatest width, rounded apically, rugulose; upper mesepisternum with strong longitudinal sculpture; fine foveae separating mesepisternum and mesepimeron extending from base of wing to coxal cavity; lower mesepisternum finely reticulate-punctate; mesepimeral hook longitudinally keeled; tegula with fine transverse striae; $R_{1}$ in forewing distinctly separated from costal margin, extending only halfway from $\mathrm{R}$ to margin; apex of forewing only reaching midpoint of $\mathrm{T} 4 ; \mathrm{R}$ in hindwing with tracheate section long, nearly reaching hamuli; tibiae with fine, semidecumbent spines on outer surface.

Metasoma (fig. 31) 4.5 times longer than greatest width; T1 distinctly wider than long; T1-T3, T6 longitudinally rugose, sculpture effaced medially on T4-T5; female T6 with large, wide, semioval apical emargination, width greater than depth, T6 anterormedially with field of granulate microsculpture.

Diagnosis: Most similar to N. pecki, with which it shares the moderately elongate A3, only slightly longer than A2; distinguished from it by the black metasoma and the absence of the occipital carina medially.

ETYMOlogy: The name elongata refers to the long and narrow body.

Material EXAmined: Holotype female: SOUTH AFRICA: Cape Province, Grahamstown, Stowan; 5 March 1972, D. J. Brothers, C. Jacot-Guillarmad, OSUC 146411, deposited in SANC.

\section{Nixonia flavocincta, new species} Figures 4, 7, 32-35

Description: Holotype female. Length: $4.5 \mathrm{~mm}$; body generally black, with posterior margin of pronotum, scutellum, propodeal tooth, apex of T1-T4 with narrow yellow bands; femora, tibiae yellow to orange; tarsi largely yellow, apical tarsomeres darker; A1A4 yellow, A5-A14 dark brown to black; tegula yellow; palpi light brown; wings partially infuscate, brownish.

Head (figs. 7, 32-34) moderately transverse in dorsal view, width 1.6 times length; vertex rugulose-punctate, with granular microsculpture; lateral ocellus contiguous with inner orbit; POL 0.6 times LOL; occiput rugulose- punctate, with reticulate microsculpture; occipital carina present medially as low, crenulate carina; frons (fig. 33) finely rugulosepunctate near inner orbits, otherwise shining, covered with dense transverse wrinkles; frons very narrow, IOS 0.4 times greatest length of eye; toruli separated by distance subequal to diameter of torulus; frons between toruli not projecting, flat; rim of torulus evenly raised; apical margin of clypeus straight; area below eye (in normal position of malar sulcus) with fine granulate microsculpture; cheeks laterad of malar area rugose-punctate, with distinct longitudinal sculpture; mandible short, bidentate, upper tooth only slightly longer than lower, without dense basal tuft of setae; maxillary palpal segment 4 distinctly expanded medially, subtriangular; A1 finely reticulate, greatest width basad of midpoint of segment; length of A3 0.6 times of A2 (fig. 4).

Mesosoma (figs. 32, 34) as high as wide, length 1.5 times height; pronotal shoulders coarsely punctate; lateral surface of pronotum finely punctate; netrion finely punctate, with weak longitudinal sculpture; mesoscutum deeply punctate, with fine reticulate microsculpture; parapsidal lines present; scutellum coarsely punctate, with reticulate microsculpture, with distinct fine longitudinal elements in posterior half; median propodeal tooth moderately wide, two times as long as wide, pointed apically, longitudinally carinate; upper mesepisternum finely punctate, without longitudinal sculpture; fine foveae separating mesepisternum and mesepimeron extending from base of wing to coxal cavity; lower mesepisternum finely reticulate-punctate; mesepimeral hook longitudinally keeled; tegula with granular microsculpture; apex of $\mathrm{R}_{1}$ reaching costal margin; apex of forewing slightly surpassing apex of $\mathrm{T} 4 ; \mathrm{R}$ in hindwing with tracheate section short, broadly separated from hamuli by distance greater than its length; tibiae with fine, semidecumbent spines on outer surface.

Metasoma (fig. 35) 3.5 times longer than greatest width; T1 distinctly wider than long; T1-T3, T6 longitudinally rugose, sculpture effaced medially on T4-T5; female T6 with moderately large apical emargination, width greater than depth, T6 anteromedially without distinctive field of microsculpture.

Diagnosis: This species shares with $N$. sicaria the very narrow IOS and the short A3. 


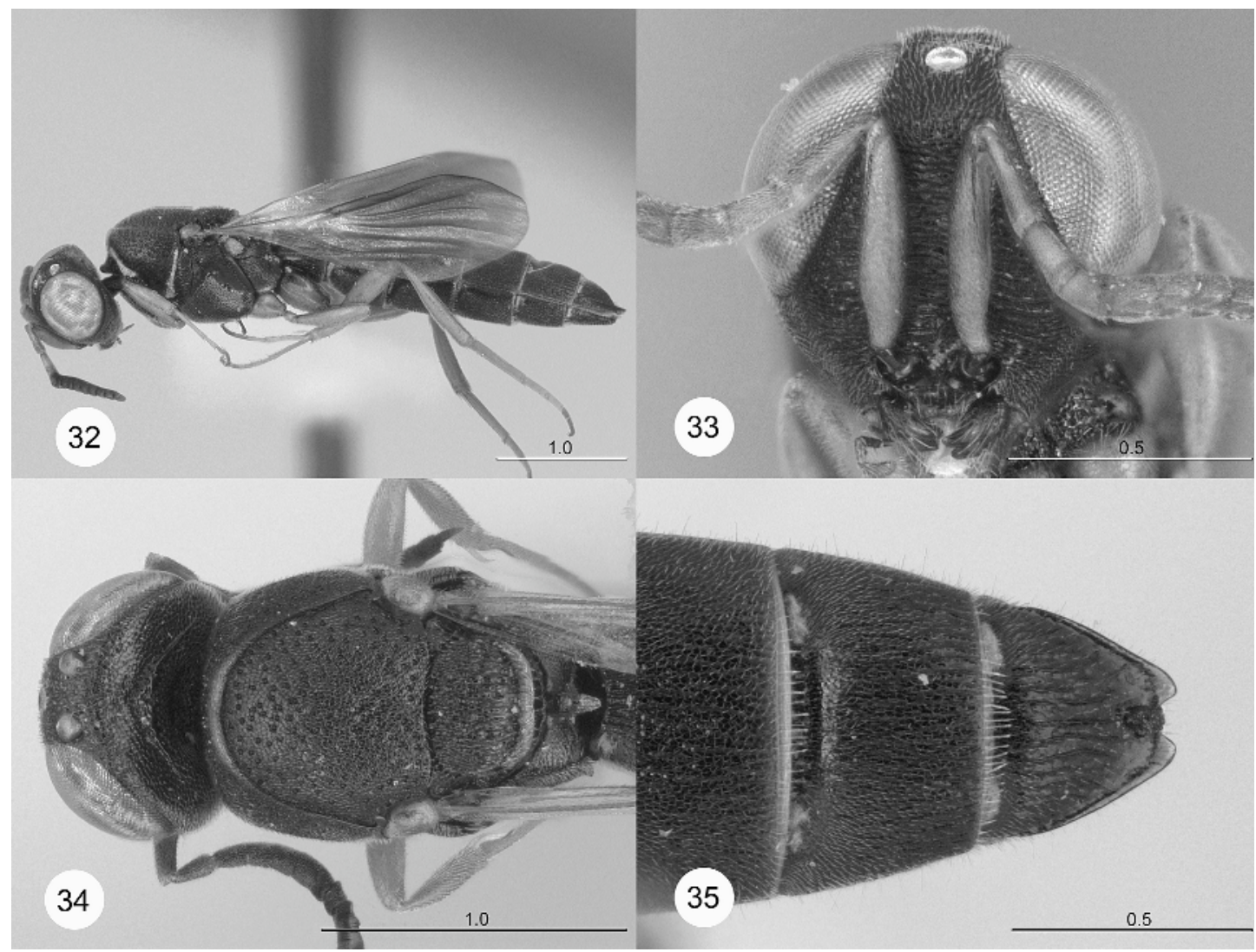

Figs. 32-35. Nixonia flavocincta, n.sp. 32. Lateral habitus, holotype female (OSUC 146462). 33. Head, frontal view, holotype female (OSUC 146462). 34. Head and mesosoma, dorsal view (OSUC 146455). 35. Apex of metasoma, dorsal view, holotype female (OSUC 146462). Scale in millimeters.

It may be easily distinguished from this and all other known species of Nixonia by the yellow banding on the mesosoma and metasoma, and the bright yellow antennal scape.

ETYMOLOGY: From flavo-, "yellow", and cincta, "girdled", referring to the distinctive yellow bands on the mesosoma and metasoma.

Material Examined: Holotype female: NAMIBIA: Windhoek District, Khomas Reg., Oase at Gaub River, $730 \mathrm{~m}, 23^{\circ} 29^{\prime} \mathrm{S}$ $15^{\circ} 46^{\prime}$ E, 22-29.XI.1996, M. E. Irwin, E. I. Schlinger, E. Marais, malaise trap in riverine vegetation, OSUC 146462, deposited in UCDC. Paratypes: 1 female, 1 male with same data as holotype, OSUC 146460-146461. NAMIBIA: E. Gobabeb, 21.XII-16.I.1979, R. A. Wharton, OSUC 146455, 1 male. Deposited in CNCI, UCDC.
Nixonia gigas, new species

Figures 36-41

Description: Holotype female. Length $9.0 \mathrm{~mm}$; body generally black; fore-, midfemora largely black, hindfemur dark red; tibiae, tarsi dark red; antenna entirely black; tegula black; palpi blackish; wings infuscate throughout, brownish.

Head (figs. 36-38, 40) transverse in dorsal view, width 2.1 times length; vertex rugulosepunctate, shining; OOL short, lateral ocellus separated from inner orbit by less than one ocellar diameter; POL 1.4 times LOL; occiput rugulose-punctate, shining; occipital carina present medially as low, crenulate carina; frons (fig. 37) rugulose-punctate, shining, above toruli with dense transverse wrinkles; frons somewhat narrow, IOS 0.9 times great- 


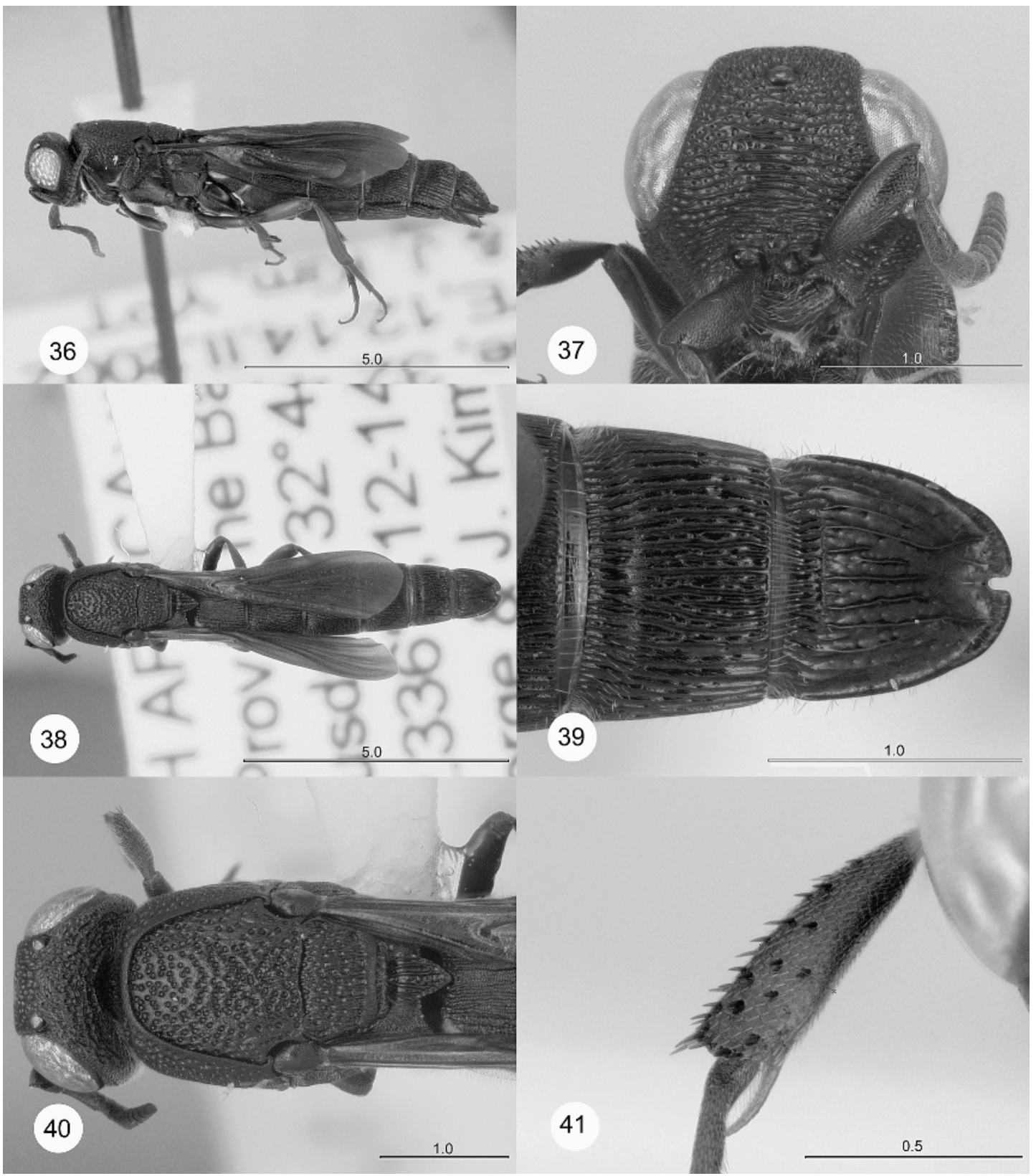

Figs. 36-41. Nixonia gigas, n.sp., holotype female (OSUC 146428). 36. lateral habitus. 37. Head, frontal view. 38. Dorsal habitus. 39. Apex of metasoma, dorsal view. 40. Head and mesosoma, dorsal view. 41. Foretibia, frontal view. Scale in millimeters.

est length of eye; toruli separated by distance of approximately one-half diameter of torulus; frons between toruli not projecting, flat; rim of torulus raised dorsally; apical margin of clypeus straight; area below eye (in normal position of malar sulcus) with fine granulate microsculpture; cheeks laterad of malar area rugose-punctate, with distinct longitudinal 
sculpture; mandible short, bidentate, upper tooth only slightly longer than lower, without dense basal tuft of setae; maxillary palpal segment 4 distinctly expanded medially, subtriangular; A1 finely reticulate, greatest width in apical two-thirds of segment; length of A3 1.7 times length of A2.

Mesosoma (figs. 36, 38, 40) as high as wide, length 1.7 times height; pronotal shoulders coarsely punctate; lateral surface of pronotum coarsely punctate; netrion punctate-rugulose, with strong longitudinal sculpture; mesoscutum deeply punctate, with fine reticulate microsculpture; parapsidal lines present; scutellum: coarsely punctate, with reticulate microsculpture, with distinct fine longitudinal elements in posterior half; median propodeal tooth triangular, broad, length 1.2 times maximum width, rounded apically, longitudinally carinate; upper mesepisternum with strong longitudinal sculpture; fine foveae separating mesepisternum and mesepimeron extending from base of wing to coxal cavity; lower mesepisternum finely reticulate-punctate; mesepimeral hook longitudinally keeled; tegula finely punctate; $\mathrm{R}_{1}$ in forewing distinctly separated from costal margin, extending only halfway from $\mathrm{R}$ to margin; apex of forewing extending near apex of $\mathrm{T} 4 ; \mathrm{R}$ in hindwing with tracheate section long, nearly reaching hamuli; outer surface of tibiae with numerous stout, erect spines (fig. 41).

Metasoma (figs. 38, 39) 4.2 times longer than greatest width; T1 distinctly wider than long; terga longitudinally rugose; female T6 with very narrow apical emargination, depth greater than width, T6 anteromedially without distinctive field of microsculpture.

Diagnosis: This species is distinguished from other darkly colored species of Nixonia in southern Africa by its large size, the strong spines on the fore- and midtibiae, and the very narrow excision in the female T6.

ETYMOLOGY: The specific epithet refers to the size of this species, the largest in the genus Nixonia.

MATERIAL ExAmined: Holotype female: SOUTH AFRICA: Western Cape Prov., The Baths S. of Citrusdale [sic], $32^{\circ} 44.044^{\prime} \mathrm{S}$ $19^{\circ} 02.336^{\prime} \mathrm{E}, 12-14 . \mathrm{II} .2002$, J. George, J. Kim, yellow pan trap, OSUC 146428, deposited in SANC.

\section{Nixonia krombeini, new species}

Figures 5, 11, 12, 42-45

DesCription: Holotype female. Length $5.5 \mathrm{~mm}$; body generally black; femora, tibiae, tarsi, antenna, tegula black; palpi yellowish; wings infuscate throughout, brownish.

Head (figs. 12, 42-44) moderately transverse in dorsal view, width 1.8 times length; vertex coarsely punctate, with granulate microsculpture; OOL short, lateral ocellus separated from inner orbit by distance less than one ocellar diameter; POL 1.2 times LOL; occiput coarsely punctate, with granulate microsculpture; occipital carina strongly raised, massive, crenulate; frons (fig. 43) rugulose-punctate, shining, above toruli with few transverse wrinkles medially; frons somewhat narrow, IOS 0.9 times greatest length of eye; toruli separated by distance of approximately one-half diameter of torulus; frons between toruli not projecting, flat; rim of torulus raised dorsally; apical margin of clypeus with blunt medial projection; area below eye (in normal position of malar suclus) with fine granulate microsculpture; cheeks laterad of malar area coarsely punctate, without longitudinal sculpture; mandible (fig. 11) short, bidentate, upper tooth only slightly longer than lower, without dense basal tuft of setae; maxillary palpal segment 4 distinctly expanded medially, subtriangular; A1 finely reticulate, greatest width in apical two-thirds of segment; length of A3 1.7 times length of A2 (fig. 5).

Mesosoma (figs. 42, 44) as high as wide, length 1.6 times height; pronotal shoulders coarsely punctate; lateral surface of pronotum coarsely punctate; netrion punctate-rugulose, with strong longitudinal sculpture; mesoscutum deeply punctate, with fine reticulate microsculpture; parapsidal lines present; scutellum coarsely punctate, with reticulate microsculpture, without longitudinal sculpture; median propodeal tooth rhomboidal, length 1.5 times greatest width, rounded apically, rugulose; upper mesepisternum with strong longitudinal sculpture; fine foveae separating mesepisternum and mesepimeron extending from base of wing to coxal cavity; lower mesepisternum finely reticulate-punctate; mesepimeral hook longitudinally keeled; tegula finely punctate; apex of $\mathrm{R}_{1}$ reaching costal 


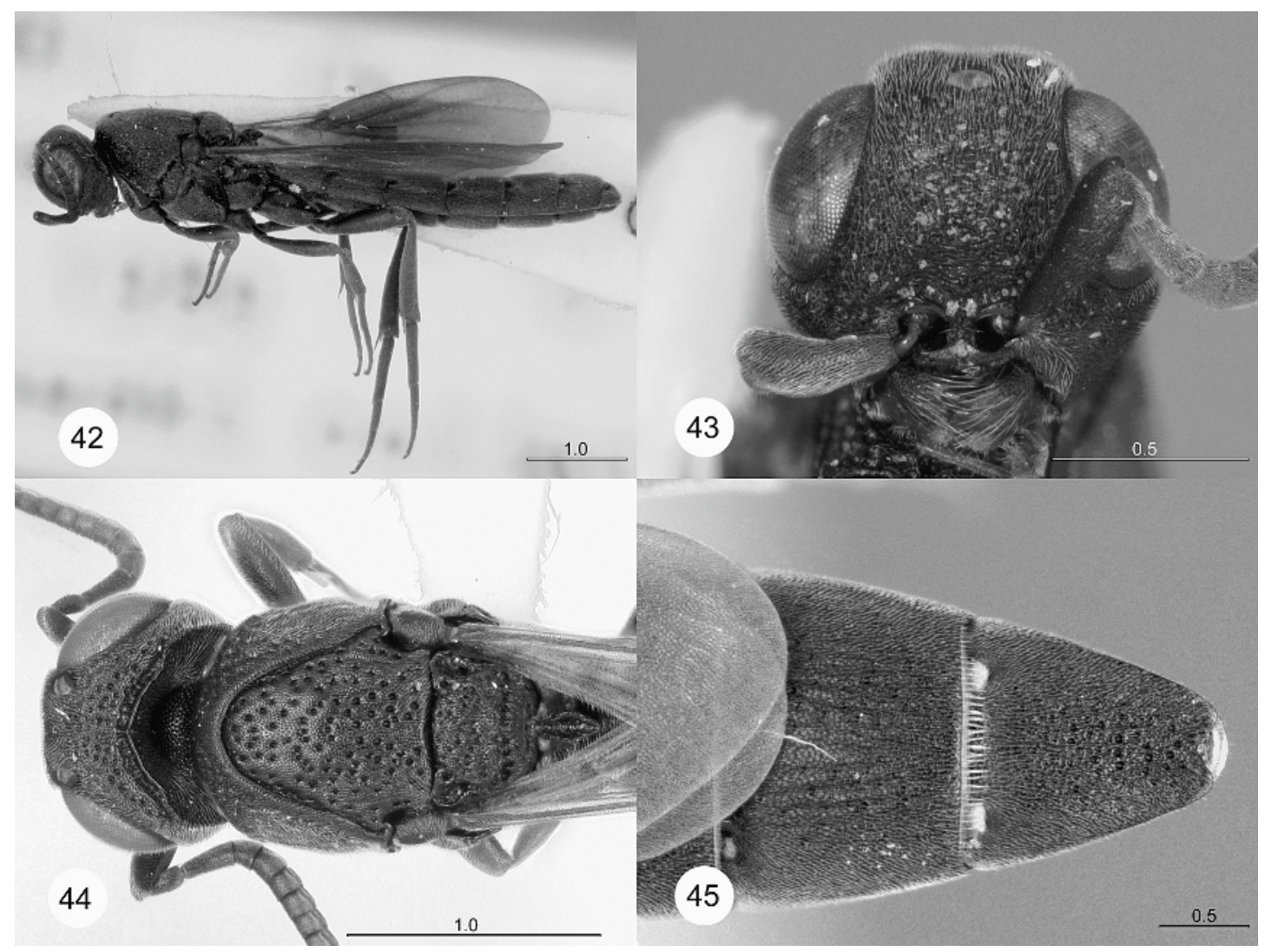

Figs. 42-45. Nixonia krombeini, n.sp. 42. Lateral habitus (CASENT 2042618). 43. Head, frontal view (CASENT 2042618). 44. Head and mesosoma, dorsal view (OSUC 149450). 45. Apex of metasoma, dorsal view (OSUC 149450). Scale in millimeters.

margin; apex of forewing slightly surpassing apex of $\mathrm{T} 4 ; \mathrm{R}$ in hindwing with tracheate section long, nearly reaching hamuli; tibiae with fine, semidecumbent spines on outer surface.

Metasoma (fig. 45) 4.6 times longer than greatest width; T1 distinctly wider than long; T1-T5 irregularly longitudinally rugose, T6 punctate; female T6 with moderately large apical emargination, width greater than depth, T6 anteromedially with field of granulate microsculpture.

Diagnosis: This species shares with $N$. pecki the strongly developed occipital carina. It may be distinguished by the uniformly black body and the extensive reticulate microsculpture on the body.

ETYMOLOGY: Named in honor of Karl V. Krombein, king of aculeate researchers.
Material Examined: Holotype female: SRI LANKA: Antiquities Site, Padaviya, Anuradhapura Dist., North Central Prov., 20-23.VII.1978, K. V. Krombein, T. Wijesinhe, L. Jayawickrema, V. Kulasekare, malaise trap, OSUC 146429. Deposited in USNM. Paratypes: INDIA: Haldwani Dist., Kumaon [Uttaranchal], India, H.G.C., 1 female, OSUC 151680. LAOS: Wapikhamthong Prov., Wapi, 15.IV.1967, light trap, native collector, 1 female, OSUC 150672. SRI LANKA: 1 male, 1 female with same data as holotype, OSUC 146433, OSUC 146438. China Bay, 0-30 m, Trincomalee, Trincomalee Distr., North Eastern Prov., 24.VII.1978, K. V. Krombein, female, OSUC 146432. Mahaweli Ganga, Victoria-Randenigala-Rantambe Sanct., $7^{\circ} 12^{\prime} \mathrm{N} 80^{\circ} 57^{\prime} \mathrm{E}$, Kandy Dist. Central Prov., 25-29.VIII.1999, M. S. Was- 
bauer, J. Wasbauer, OSUC 146458. Rajawaka, Ratnapura Dist., Sabaragamuwa Prov., 20.VI.1976, K. V. Krombein, P. B. Karunaratne, S. Karunaratne, female, OSUC 146431. Ritigala Strict Natural Reserve, Anuradhapura Dist. North Central Prov., 19.IX.1980, K. V. Krombein, P. B. Karunaratne, T. Wijesinhe, L. Jayawickrema, V. Gunawardane, 1 male, 1 female, OSUC 146430, OSUC 146439. Uggalkatota, $350 \mathrm{~m}$, Ratnapura Dist., Sabaragamuwa Prov., 24.VI. 1978, K. V. Krombein, female, OSUC 146434. Victoria-Randenigala-Rantambe Sanctuary, $7^{\circ} 12.624^{\prime} \mathrm{N} 80^{\circ} 56.540^{\prime} \mathrm{E}$, Kandy Dist., Central Prov., 23-30.VIII.1999, M. S. Wasbauer, J. S. Wasbauer, malaise trap, 3 males, 3 females, OSUC 146435, OSUC 146436, OSUC 146437, OSUC 146440, OSUC 146441, OSUC 146442. THAILAND: Chiang Dao, Chiang Mai, 27.III.1993, G. R. Ballmer, at window, OSUC 146447, OSUC 146448. Doi Inthanon Nat. Park, $70 \mathrm{~km}$ SW Chiang Mai, $126 \mathrm{~m}$, 31.I-7.II.1989, T. W. Thormin, malaise/pan trap, OSUC 146445. Doi Suthep, Chiang Mai, 1-2.V.1989, W. J. Pulawski, CASENT 2042618. Khao Yai Nat. Park, 10-17.II.1989, T. W. Thormin, pan trap, OSUC 146443, OSUC 146444, OSUC 146446. $60 \mathrm{~km} \mathrm{~S}$ Nakhon Ratchasima, Nakhon Ratchasima, 2-4.III.1971, P. J. Spangler, P. Spangler, OSUC 149450, 1 female. Sakhonakora Province, Phupamam National Park, GPS48Q0390822, UTM188b394 273M, 12-16.III.2005, malaise trap, OSUC 168995, 168996, 1 male, 1 female. VIETNAM: $50 \mathrm{~km}$ SW Pleiku, 250 m, Gia Lai, 14.V.1960, S. Quate, L. W. Quate, 1 female, OSUC 150673. Deposited in CNCI, USNM, CASC, UCDC, BMNH, BPBM.

\section{Nixonia lamorali, new species} Figures 46-48

DesCription: Holotype male. Length: $7.0 \mathrm{~mm}$; body generally black; femora, tibiae, tarsi, antenna, tegula black; palpi brown; wings infuscate throughout, brownish.

Head (figs. 46-48) transverse in dorsal view, width 2.4 times length; vertex rugulose-punctate, with granular microsculpture; OOL short, lateral ocellus separated from inner orbit by less than one ocellar diameter; POL
1.5 times LOL; occiput rugulose-punctate, with reticulate microsculpture; occipital carina not developed; frons (fig. 47) rugulose-punctate, shining, above toruli with few transverse wrinkles medially; frons somewhat narrow, IOS 0.9 times greatest length of eye; toruli closely approximated, separated by distance less than half torulus diameter, frons between toruli not projecting, flat; rim of torulus evenly raised; apical margin of clypeus with blunt medial projection; area below eye (in normal position of malar sulcus) with fine granulate microsculpture; sculpture of cheeks laterad of malar area rugose-punctate, with distinct longitudinal sculpture; mandible short, bidentate, upper tooth only slightly longer than lower, without dense basal tuft of setae; maxillary palpal segment 4 distinctly expanded medially, subtriangular; A1 finely reticulate, greatest width beyond apical 0.6 of segment; length of A3 1.6 times of A2.

Mesosoma (figs. 46, 48) as high as wide, length 1.4 times height in lateral view; pronotal shoulders coarsely punctate; lateral surface of pronotum coarsely punctate; netrion punctate-rugulose, with strong longitudinal sculpture; mesoscutum deeply punctate, with fine reticulate microsculpture; parapsidal lines absent; scutellum coarsely punctate, with reticulate microsculpture, with distinct fine longitudinal elements in posterior half; median propodeal tooth rhomboidal, length 1.2 times maximum width, rounded apically, rugulose; upper mesepisternum with strong longitudinal sculpture; fine foveae separating mesepisternum and mesepimeron extending from base of wing to coxal cavity; lower mesepisternum finely reticulate-punctate; mesepimeral hook smooth; tegula finely punctate; $\mathrm{R}_{1}$ in forewing distinctly separated from costal margin, extending only halfway from $\mathrm{R}$ to margin; apex of forewing extending near apex of $\mathrm{T} 5 ; \mathrm{R}$ in hindwing with tracheate section long, nearly reaching hamuli; tibiae with fine, semidecumbent spines on outer surface.

Metasoma 2.7 times longer than greatest width; T1 distinctly wider than long; T1-T4 longitudinally rugose, T5 apex coarsely punctate.

Diagnosis: Distinguished from $N$. watsha$m i$ by the narrow IOS, which is less than the greatest length of the compound eye. 


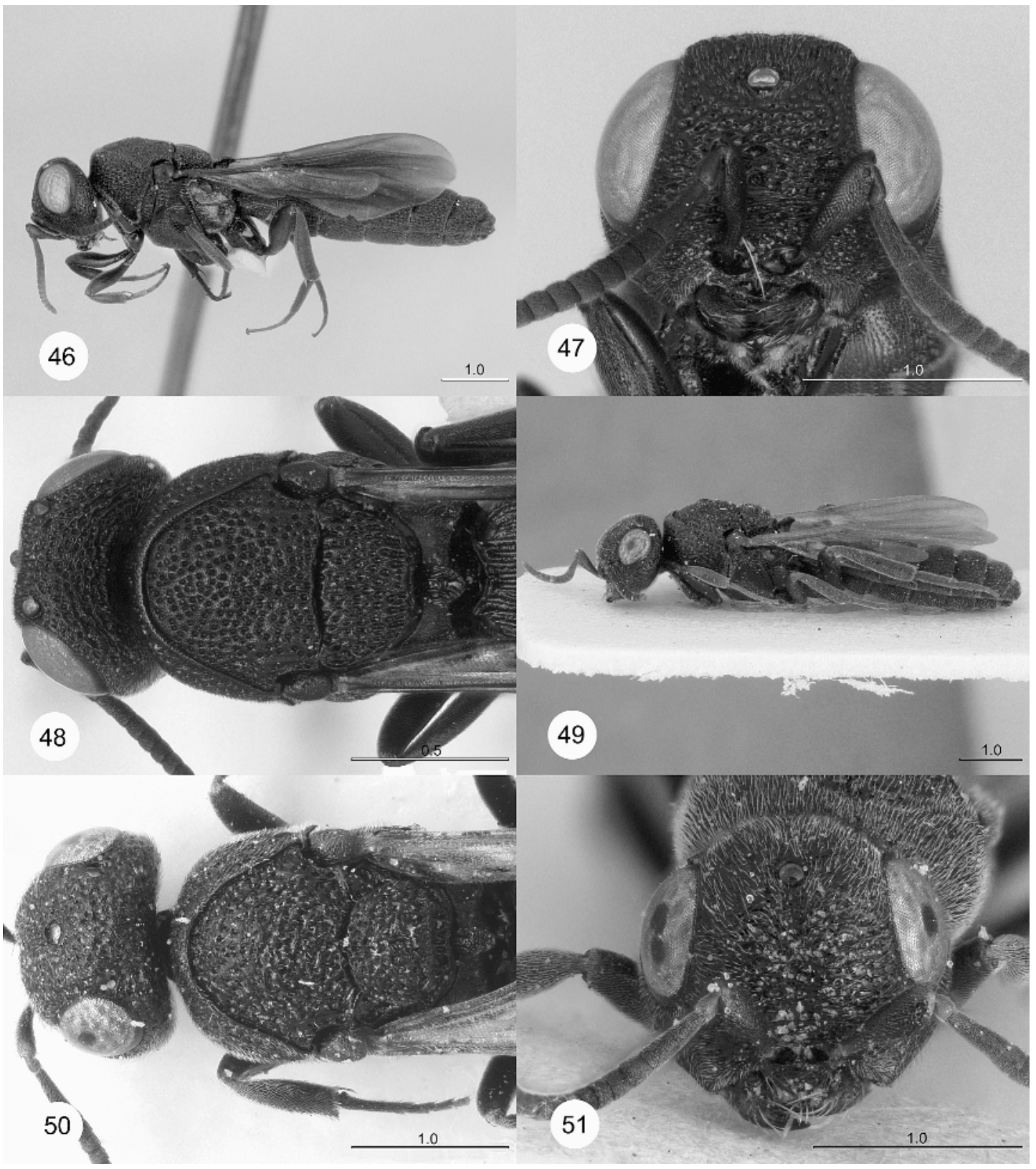

Figs. 46-51. 46. Nixonia lamorali, n.sp., lateral habitus, holotype male (OSUC 146449). 47. N. lamorali, head, frontal view, holotype male (OSUC 146449). 48. N. lamorali, head and mesosoma, dorsal view, holotype male (OSUC 146449). 49. $N$. priesneri, n.sp., lateral habitus, holotype male (OSUC 146450). 50. $N$. priesneri, head and mesosoma, dorsal view, holotype male (OSUC 146450). 51. N. priesneri, head, frontal view, holotype male (OSUC 146450). Scale in millimeters. 
Etymology: Named for Bruno H. Lamoral, distinguished South African spider specialist and one of the collectors of the unique holotype.

Material Examined: Holotype male: SOUTH AFRICA: Horingsgat, $30^{\circ} 18^{\prime} \mathrm{S}$ $18^{\circ} 05^{\prime} \mathrm{E}$, Namaqualand, N. Cape Prov., 25.II.1979, B. Lamoral, I. Bampton, malaise trap, OSUC 146449, deposited in CNCI.

\section{Nixonia pecki, new species}

Figures 2, 3, 52-55

DesCRIPTION: Holotype female. Length $6.4 \mathrm{~mm}$; head, mesosoma, base of T1, T6 black, apex of T1, T2-T5 dark red; femora, tibiae, tarsi dark red; antenna entirely black; tegula black to dark brown; palpi light brown; wings infuscate throughout, dark gray.

Head (figs. 2, 3, 52-54) moderately transverse in dorsal view, width 1.6 times length; vertex coarsely punctate, with granulate microsculpture; OOL short, lateral ocellus separated from inner orbit by less than one ocellar diameter; POL 1.4 times LOL; occiput coarsely punctate, with granulate microsculpture; occipital carina strongly raised, massive, crenulate; frons (fig. 53) rugulose-punctate, shining, above toruli with dense transverse wrinkles; frons fairly broad, IOS equal to greatest length of eye; toruli separated by distance of approximately one-half diameter of torulus, frons between toruli not projecting, flat; rim of torulus evenly raised; apical margin of clypeus broadly convex; area below eye (in normal position of malar sulcus) with fine granulate microsculpture; cheeks laterad of malar area coarsely punctate, without longitudinal sculpture; mandible short, bidentate, upper tooth only slightly longer than lower, without dense basal tuft of setae; maxillary palpal segment 4 distinctly expanded medially, subtriangular; A1 finely reticulate, greatest width beyond apical 0.6 of segment; length of A3 1.1 times length of A2.

Mesosoma (figs. 2, 3, 52, 54) as high as wide, length 1.4 times height in lateral view; pronotal shoulders coarsely punctate; lateral surface of pronotum with fine longitudinal rugulosity; netrion punctate-rugulose, with strong longitudinal sculpture; mesoscutum deeply punctate, with fine reticulate microsculpture; parapsidal lines present; scutellum coarsely punctate, with reticulate microsculpture, without longitudinal sculpture; median propodeal tooth moderately wide, two times as long as wide, pointed apically, longitudinally carinate; upper mesepisternum with strong longitudinal sculpture; fine foveae separating mesepisternum and mesepimeron extending from base of wing to coxal cavity; lower mesepisternum coarsely reticulate-punctate; mesepimeral hook longitudinally keeled; tegula finely punctate; apex of $\mathrm{R}_{1}$ in forewing almost reaching costal margin; apex of forewing slightly surpassing apex of $\mathrm{T} 4 ; \mathrm{R}$ in hindwing with tracheate section short, broadly separated from hamuli by distance greater than its length; tibiae with fine, semidecumbent spines on outer surface.

Metasoma (figs. 3, 55) 3.4 times longer than greatest width; T1 distinctly wider than long; terga longitudinally rugose; apical emargination of female T6 moderately large, width greater than depth, female T6 anteromedially with field of granulate microscupture.

Diagnosis: This species may be distinguished from most other species of Nixonia by the massively expanded occipital carina and the red basal metasomatic segments in the female.

ETyMOLOGY: Named in honor of Stewart Peck, collector extraordinaire.

Material Examined: Holotype female: BOTSWANA: Central Dist., Serowe, I.1985, P. Forchhammer, OSUC 146422, deposited in SANC. Paratypes: BOTSWANA: Central Dist., Serowe, X.1984, P. Forchhammer, 1 female, X.1984, OSUC 146423. SOUTH AFRICA: Gauteng, Van Riebeek Natuurreservaat, $25^{\circ} 52^{\prime} \mathrm{S} 28^{\circ} 16^{\prime} \mathrm{E}$, 5.I.1996, W. J. Pulawski, 2 females, CASENT 2042624, CASENT 2042622. Gauteng, Hartbeeshoek Radio Station, $25^{\circ} 53^{\prime} \mathrm{S} 27^{\circ} 41^{\prime} \mathrm{E}, \sim 45 \mathrm{~km}$ WSW Pretoria, 10.I.1996, W. J. Pulawski, 2 females, 1 male, CASENT 2042621, CASENT 2042623, CASENT 2042619. Limpopo, Klaserierivier, Klaserie Nature Reserve, 30.I.1974, W. W. Middlekauff, 1 male, CASENT 2042625. Limpopo, Lapalala Wilderness Reserve, $23.51^{\circ} \mathrm{S} 28.17^{\circ} \mathrm{E}, 21-23 . I .1987, \mathrm{R}$. B. Kimsey, 1 female, OSUC 146459. Transvaal, Guernsey Farms, 15 km NW Klaserie, 


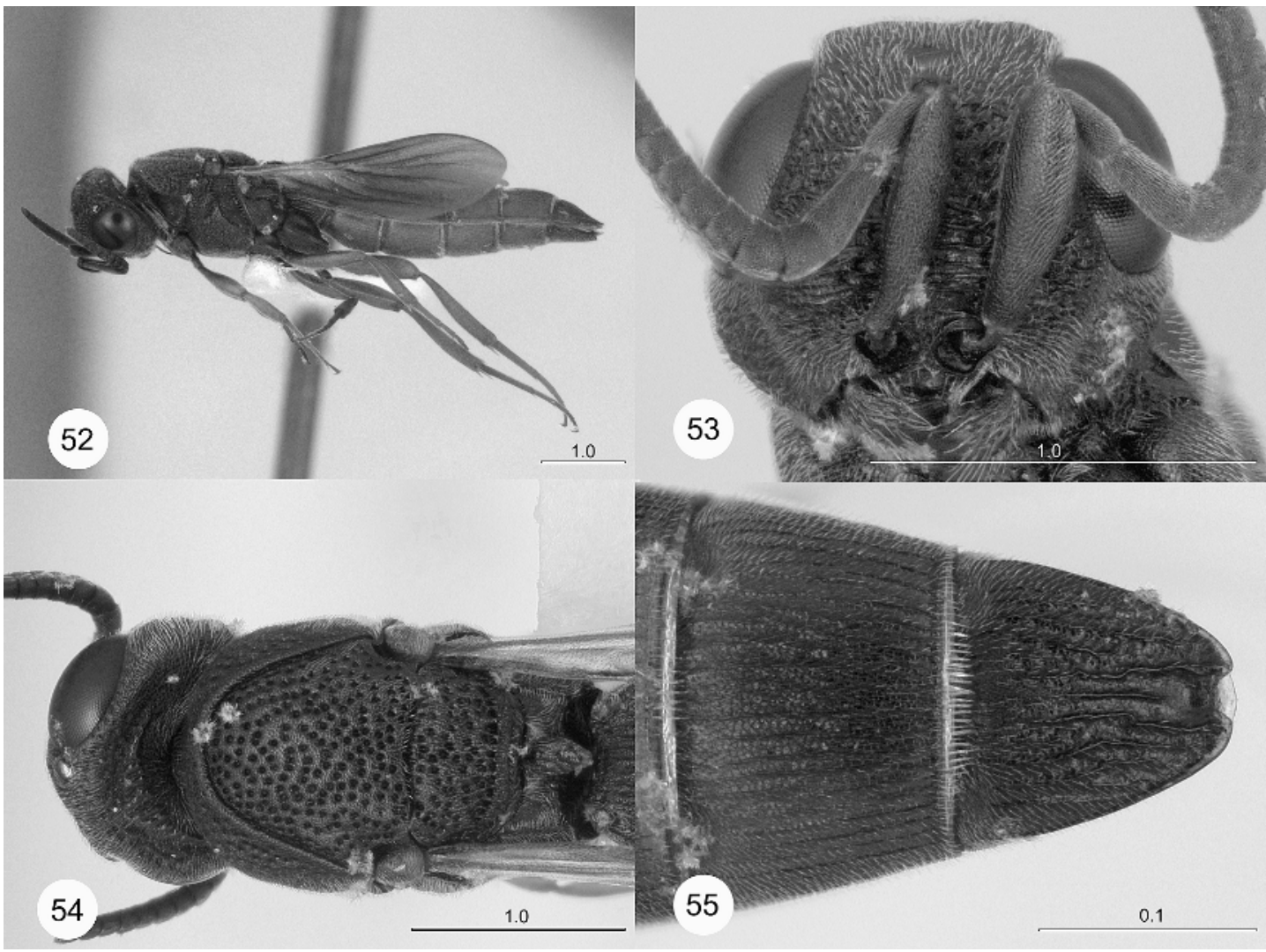

Figs. 52-55. Nixonia pecki, n.sp. (OSUC 146419). 52 Lateral habitus. 53. head, frontal view. 54. Head and mesosoma, dorsal view. 55. Apex of metasoma, dorsal view. Scale in millimeters.

19-31.X.1985, S. Peck, J. Peck, malaise trap/ flight intercept trap, 1 female, 2 males, OSUC 146419, OSUC 146420, OSUC 146421. ZIMBABWE: Leighwoods, $20^{\circ} 26^{\prime} \mathrm{S} 28^{\circ} 15^{\prime} \mathrm{E}$, $52 \mathrm{~km}$ SW Bulawayo, 31.XII.1995, W. J. Pulawski, 1 female, CASENT 2042620. Deposited in CNCI, CASC, UCDC, SANC.

\section{Nixonia pretiosa Masner} Figures 56-59

Nixonia pretiosa Masner, 1958: 103. Original description. Masner, 1965: 85 (type information).

Description: Holotype female. Length: $5.5 \mathrm{~mm}$; head, ventral portion of mesosoma, entire metasoma black, dorsal portion of pronotum, mesonotum brownish red; femora, tibiae, tarsi, tegula reddish brown; A1-A3 reddish brown, antenna otherwise dark brown to black; palpi yellow; wings partially infuscate, brownish.
Head (figs. 56-58) moderately transverse in dorsal view, width 1.5 times length; vertex rugulose-punctate, shining; OOL obsolete, lateral ocellus contiguous with inner orbit; LOL > POL; occiput rugulose-punctate, shining; occipital carina not developed; frons (fig. 57) rugulose-punctate, shining, above toruli with dense transverse wrinkles; frons broad, IOS 1.2 times greatest length of eye; toruli separated by distance subequal to diameter of torulus, frons between toruli not projecting anteriorly, flat; rim of torulus evenly raised; apical margin of clypeus with blunt medial projection; area below eye (in normal position of malar sulcus) with granular microsculpture; sculpture of cheeks laterad of malar area with slight longitudinal orientation of sculpture; mandible moderately long, bidentate, upper tooth only slightly longer than lower tooth, without dense basal tuft of setae; 


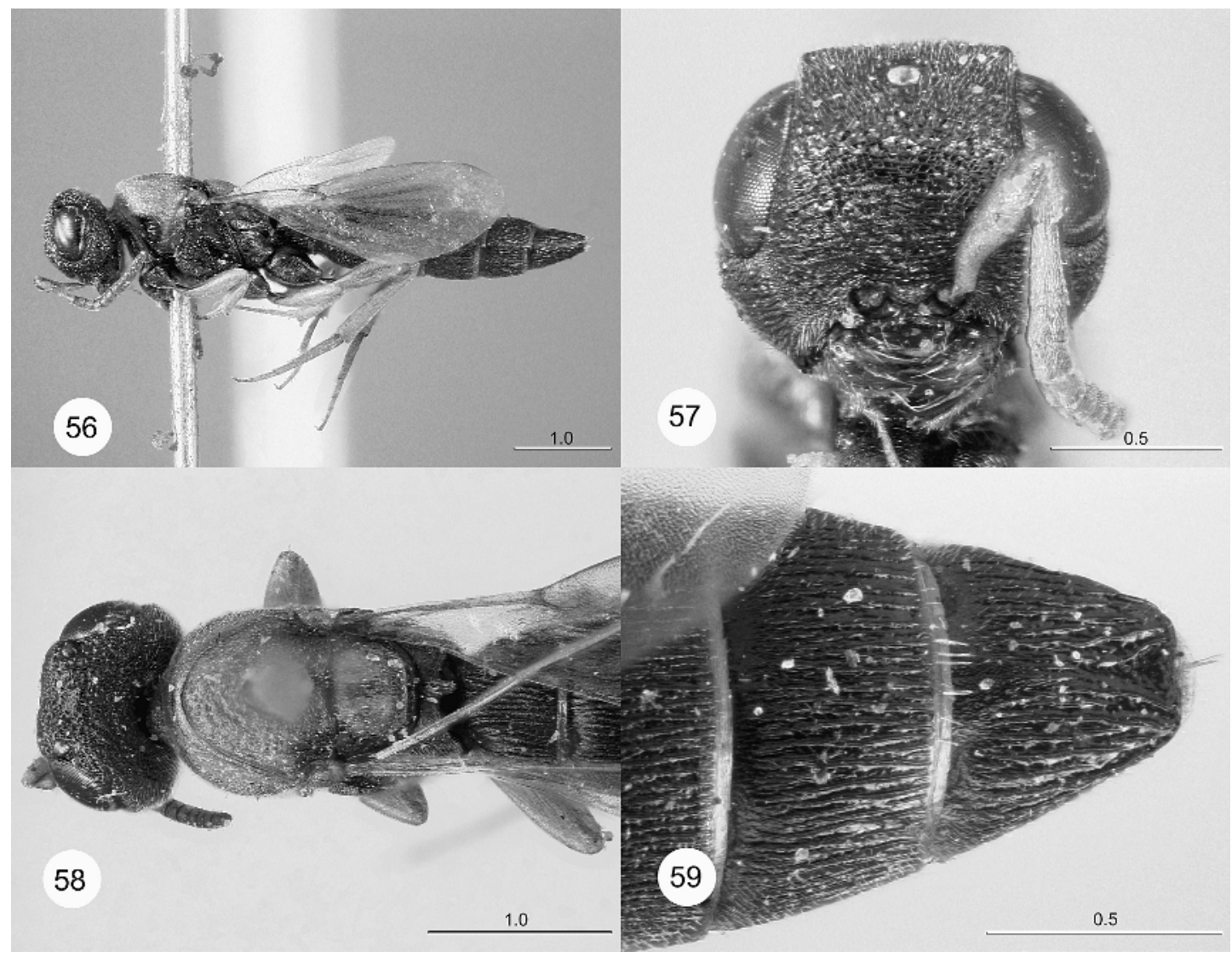

Figs. 56-59. Nixonia pretiosa Masner, holotype female (BMNH 9.546). 56. Lateral habitus. 57. Head, frontal view. 58. Head and mesosoma, dorsal view. 59. Apex of metasoma, dorsal view. Scale in millimeters.

maxillary palpal segment 4 distinctly expanded medially, subtriangular; A1 finely reticulate, greatest width at midpoint of segment; length of A3 1.2 times length of A2.

Mesosoma (figs. 56, 58) height 1.1 times length 1.5 times height; pronotal shoulders rugose-punctate; lateral surface of pronotum with fine longitudinal rugulosity; netrion with deep punctures only; mesoscutum rugosepunctate, without transverse sculpture, shining; parapsidal lines present; scutellum rugosepunctate, with fine longitudinal elements in posterior half; median propodeal tooth relatively narrow, distinctly longer than wide, with apical emargination, longitudinally carinate; upper mesepisternum with strong longitudinal sculpture; fine foveae separating mesepisternum and mesepimeron extending from base of wing to coxal cavity; lower mesepisternum finely reticulate-punctate; mesepimeral hook smooth; tegula with granular microsculpture; $\mathrm{R}_{1}$ in forewing almost reaching costal margin; apex of forewing surpassing apex of $\mathrm{T} 5$; $\mathrm{R}$ in hindwing with tracheate section long, nearly reaching hamuli; tibiae with fine, semidecumbent spines on outer surface.

Metasoma (fig. 59) 3.0 times longer than greatest width; T1 distinctly wider than long; all terga longitudinally rugose; T6 with moderately large apical emargination medially, width of emargination greater than depth; base of T6 with anteromedial, longitudinally aciculate field of microsculpture.

Diagnosis: This species is very similar to $N$. watshami; it may be distinguished by the very distinctive red color of the mesosoma.

MATERIAl ExAmined: Holotype female: "Okahandja., 13-19.i.1928.; S.W. Africa. 
R.E. Turner. Brit. Mus. 1928-77.; Nixonia pretiosa /, n. gen. n. sp. holotype, Det. L. Masner, 1958; Holotypus; Holo, type, B.M. TYPE, HYM., 9.546.” Deposited in BMNH.

Nixonia priesneri, new species

Figures 49-51

DesCriPtion: Holotype male. Length $6.8 \mathrm{~mm}$; body generally black; femora, tibiae, tarsi, antenna black; tegula black to dark brown; palpi yellowish; wings infuscate throughout, brownish.

Head (figs. 49-51) moderately transverse in dorsal view, width 1.6 times length; vertex rugulose-punctate, shining; OOL short, lateral ocellus separated from inner orbit by less than one ocellar diameter; POL 1.9 times LOL; occiput rugulose-punctate, shining; occipital carina not developed; frons (fig. 51) rugulosepunctate, shining, above toruli with dense transverse wrinkles; frons broad, IOS 1.2 times greatest length of eye; toruli closely approximated, separated by less than one-half torulus diameter, frons between toruli not projecting, flat; rim of torulus evenly raised; apical margin of clypeus straight; area below eye (in normal position of malar sulcus) with fine granulate microsculpture; cheeks laterad of malar area coarsely punctate, without longitudinal sculpture; mandible elongate, bidentate, upper tooth significantly longer than lower, with dense tuft of long, coarse setae at base of mandible; maxillary palpal segment 4 cylindrical; A1 finely punctate, greatest width beyond apical 0.6 times length of segment; length of A3 2.3 times length of A2.

Mesosoma (figs. 49, 50) height 1.1 times width, length 1.3 times height in lateral view; pronotal shoulders rugose-punctate; lateral surface of pronotum coarsely punctate; netrion punctate-rugulose, with strong longitudinal sculpture; mesoscutum rugose-punctate, with distinct transverse sculpture, shining; parapsidal lines present; scutellum rugosepunctate, shining, without longitudinal sculpture; median propodeal tooth rhomboidal, length 1.5 times greatest width, rounded apically, reticulate; upper mesepisternum largely smooth, with only weakly indicated longitudinal rugulae; fine foveae separating mesepisternum and mesepimeron extending from base of wing to coxal cavity; lower mesepisternum finely reticulate-punctate; mesepimeral hook longitudinally keeled; tegula with granular microsculpture; $\mathrm{R}_{1}$ in forewing distinctly separated from costal margin, extending only halfway from $\mathrm{R}$ to margin; apex of forewing surpassing apex of $\mathrm{T} 5$; $\mathrm{R}$ in hindwing with tracheate section short, broadly separated from hamuli by distance greater than its length; tibiae with fine, semidecumbent spines on outer surface.

Metasoma 2.4 times longer than greatest width; T1 distinctly wider than long; T1-T5 longitudinally rugose, T6-T7 punctate.

Diagnosis: This species is most similar to $N$. atra, from which it may be distinguished by the distinctive transverse sculpture in the posterior portion of the mesoscutum. In addition, it may be distinguished from $N$. bini by the presence of a small, but distinct lower tooth on the mandible.

ETYMOLOGY: Named in honor of Hermann Priesner, noted expert on Hymenoptera and Thysanoptera.

Material Examined: Holotype male. EGYPT: Gebel Elba, 30.I.1933, H. Priesner, Aidel, sand dune, OSUC 146450. Deposited in USNM.

\section{Nixonia sicaria, new species Figures 60-63}

DesCRIPTION: Holotype female. Length: $4.1 \mathrm{~mm}$; body generally black; femora, tibiae yellow; tarsi dark brown; antenna entirely black; tegula black; palpi brown; wings infuscate throughout, brownish.

Head (figs. 60-62) moderately transverse in dorsal view, width 1.9 times length; vertex rugulose-punctate, with granular microsculpture; lateral ocellus contiguous with inner orbit; LOL subequal to POL; occiput rugulose-punctate, with reticulate microsculpture; occipital carina present medially as low, crenulate carina; frons (fig. 61) rugulosepunctate, shining, with dense transverse wrinkles above toruli; frons narrow, IOS 0.6 times greatest length of eye; toruli separated by distance of approximately one-half diameter of torulus; frons between toruli not projecting, flat; rim of torulus raised dorsally, laterally, 


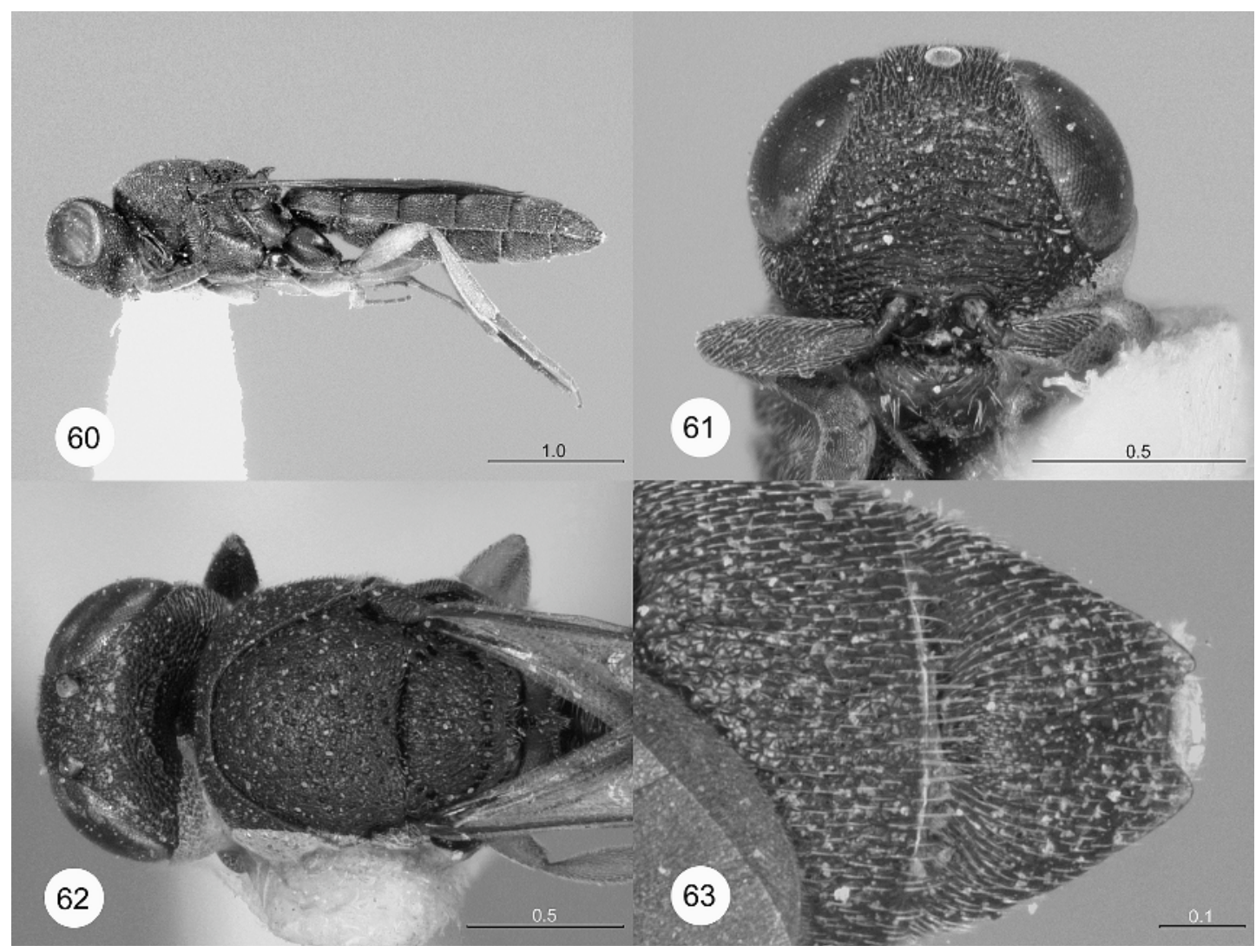

Figs. 60-63. Nixonia sicaria, n.sp., holotype female (OSUC 151679). 60. lateral habitus (image reversed). 61. Head, frontal view. 62. Head and mesosoma, dorsal view. 63. Apex of metasoma, dorsal view. Scale in millimeters.

medially; apical margin of clypeus broadly convex; area below eye (in normal position of malar sulcus) with fine granulate microsculpture; cheeks laterad of malar area rugosepunctate, with distinct longitudinal sculpture; mandible short, bidentate, upper tooth only slightly longer than lower, without dense basal tuft of setae; maxillary palpal segment 4 distinctly expanded medially, subtriangular; A1 finely reticulate, greatest width beyond apical 0.6 times length of segment; length of A3 0.6 times length of A2.

Mesosoma (figs. 60, 62) as high as wide, length 1.4 times height; pronotal shoulders coarsely punctate; lateral surface of pronotum with fine longitudinal rugulosity; netrion punctate-rugulose, with strong longitudinal sculpture; sculpture of mesoscutum deeply punctate, with fine reticulate microsculpture; parapsidal lines present; scutellum coarsely punctate, with reticulate microsculpture, with distinct fine longitudinal elements in posterior half; median propodeal tooth narrow, length 2.2 times maximum width, rugulose, rounded apically; upper mesepisternum with strong longitudinal sculpture; fine foveae separating mesepisternum and mesepimeron extending from base of wing to coxal cavity; lower mesepisternum finely reticulate-punctate; mesepimeral hook longitudinally keeled; tegula with granular microsculpture; apex of $\mathrm{R}_{1}$ in forewing almost reaching costal margin; apex of forewing extending to midpoint of $\mathrm{T} 5$; $\mathrm{R}$ in hindwing with tracheate section long, nearly reaching hamuli; tibiae with fine, semidecumbent spines on outer surface. 
Metasoma (fig. 63) 3.0 times longer than greatest width; T1 distinctly wider than long; T1-T4 longitudinally rugose, T5 apex coarsely punctate; female T6 moderately large apical emargination, width greater than depth, anteromedially with field of granulate microsculpture.

Diagnosis: Nixonia sicaria shares with $N$. flavocincta the extremely narrow interocular space, the nearly equilateral ocellar triangle, and the yellow femora and tibiae; $N$. sicaria may be distinguished by the absence of yellow bands on the mesosoma and metasoma, and the longitudinally striate upper mesepisternum.

ETymology: The epithet sicaria, Latin for "assassin", refers to the narrow, daggerlike propodeal tooth.

MATERIAL EXAMINED: Holotype female. NAMIBIA: SOUTH WEST AFRICA (W34), Windhoek, Regenstein Mt., 8.ii.1972, 7000' [2100 m], montane vegetation; Southern African Exp. B.M. 1972-1; Nixonia sp. det. A. D. Austin 1984; OSUC 151679. Deposited in BMNH.

\section{Nixonia stygica, new species} Figures 64-67

DesCriPTION: Holotype female. Length: $4.8 \mathrm{~mm}$; body generally black; femora, tibiae, tarsi, antenna, tegula black; palpi brown; wings infuscate throughout, brownish.

Head (figs. 64-66) transverse in dorsal view, width 1.9 times length; vertex rugulose-punctate, shining; lateral ocellus contiguous with inner orbit; POL 1.1 times LOL; occiput rugulose-punctate, shining; occipital carina present medially as low, crenulate carina; frons (fig. 65) rugulose-punctate, shining, above toruli with dense transverse wrinkles; frons narrow, IOS 0.7 times greatest length of eye; toruli separated by distance subequal to diameter of torulus, frons between toruli not projecting, flat; rim of torulus raised dorsally, laterally; apical margin of clypeus broadly convex; area below eye (in normal position of malar sulcus) with fine granulate microsculpture; cheeks laterad of malar area rugosepunctate, with distinct longitudinal sculpture; mandible short, bidentate, upper tooth only slightly longer than lower, without dense basal tuft of setae; maxillary palpal segment 4 distinctly expanded medially, subtriangular; A1 finely reticulate, greatest width at midpoint of segment; length of A3 1.8 times length of A2.

Mesosoma (figs. 64, 66) as high as wide, length 1.4 times height in lateral view; pronotal shoulders coarsely punctate; lateral surface of pronotum with fine longitudinal rugulosity; netrion punctate-rugulose, with strong longitudinal sculpture; mesoscutum: deeply punctate, with fine reticulate microsculpture; parapsidal lines absent; scutellum coarsely punctate, with reticulate microsculpture, without longitudinal sculpture; median propodeal tooth triangular, narrow, length 1.6 times maximum width, rounded apically, longitudinally carinate; upper mesepisternum with strong longitudinal sculpture; fine foveae separating mesepisternum and mesepimeron extending from base of wing to coxal cavity; lower mesepisternum finely reticulate-punctate; mesepimeral hook largely smooth, with few longitudinal keels; tegula finely punctate; apex of $\mathrm{R}_{1}$ in forewing reaching costal margin; apex of forewing extending to midpoint of T5; $\mathrm{R}$ in hindwing with tracheate section short, broadly separated from hamuli by distance greater than its length; tibiae with fine, semidecumbent spines on outer surface.

Metasoma (fig. 67) 3.2 times longer than greatest width; T1 distinctly wider than long; terga longitudinally rugose; female T6 moderately large apical emargination, width greater than depth, anteromedially with field of granulate microsculpture.

Additional character from male: tyloids present on A4, A5.

Diagnosis: This very dark species is most similar to $N$. corrugata. It may be distinguished by its black body and the more elongate forewing, extending nearly to the apex of T5.

ETymology: Named after the River Styx, dark river of Hades, in reference to the overall color of the animal.

Material ExAmined: Holotype female. SOUTH AFRICA: Eastern Cape Province, $43 \mathrm{~km}$ NE Willowmore, $33^{\circ} 08.31^{\prime} \mathrm{S}$ $23^{\circ} 50.48^{\prime} \mathrm{E}, 18 . \mathrm{XI}-22 . X I .1999$, M. E. Irwin et al., OSUC 146451. Deposited in SANC. Paratypes: SOUTH AFRICA: Western Cape 


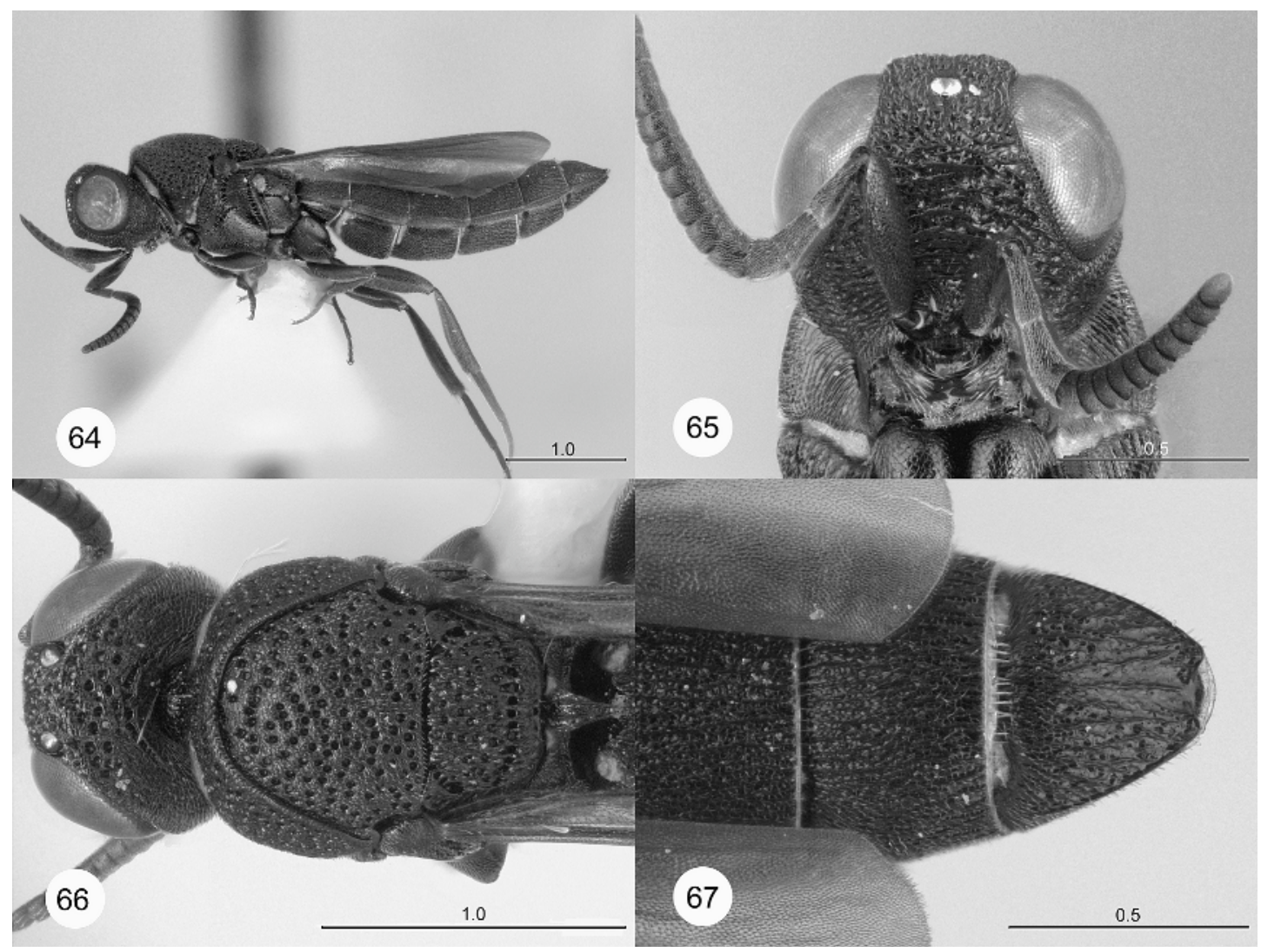

Figs. 64-67. Nixonia stygica, n.sp., holotype female (OSUC 146451). 64. Lateral habitus. 65. Head, frontal view. 66. Head and mesosoma, dorsal view. 67. Apex of metasoma, dorsal view. Scale in millimeters.

Province, $23 \mathrm{~km} \mathrm{~N}$ Oudstshoorn, $33^{\circ} 25^{\prime} 28^{\prime \prime} \mathrm{S}$ $22^{\circ} 14^{\prime} 42^{\prime \prime} \mathrm{E}, 500 \mathrm{~m}, 1-23 . X .2004$, M. E. Irwin, F. D. Parker, M. Hauser, malaise trap in wash, SA-11, OSUC 168997, 1 female. Western Cape Province, $30 \mathrm{~km}$ NE Barrydale, $33^{\circ} 14^{\prime} 49^{\prime \prime} \mathrm{S} 20^{\circ} 57^{\prime} 34^{\prime \prime} \mathrm{E}, 440 \mathrm{~m}, 1-$ 22.X.2004, malaise trap in woodland wash, OSUC 168998, 1 female. Western Cape Province, $18 \mathrm{~km} \mathrm{~S}$ Sutherland, 32 32'16"S $20^{\circ} 37^{\prime} 09^{\prime \prime} \mathrm{E}, 1390 \mathrm{~m}, 3-24 . X .2005$, M. E. Irwin, F. D. Parker, M. Hauser, malaise trap, SA 19, OSUC 168999, 169000, 1 male, 1 female. Deposited in INHS, CNCI.

Nixonia watshami, new species Figures 9, 13, 68-73

DesCription: Holotype female. Length: $5.5 \mathrm{~mm}$; body generally black; femora, tibiae, tarsi reddish brown; A1-A2, tegula brown; palpi light brown; wings partially infuscate, brownish.

Head (figs. 13, 68-70) moderately transverse in dorsal view, width 1.4 times length; vertex rugulose-punctate, shining; OOL short, lateral ocellus separated from inner orbit by less than one ocellar diameter; POL 1.6 times LOL; occiput rugulose-punctate, shining; occipital carina not developed; frons (fig. 69) rugulose-punctate, above toruli with dense transverse wrinkles; frons broad, IOS 1.1 times greatest length of eye; toruli separated by distance of approximately one-half diameter of torulus, frons between toruli not projecting anteriorly; rim of torulus evenly raised; apical margin of clypeus with blunt medial projection; area below eye (in normal position of malar sulcus) with fine granular microsculpture, distinct from surrounding 


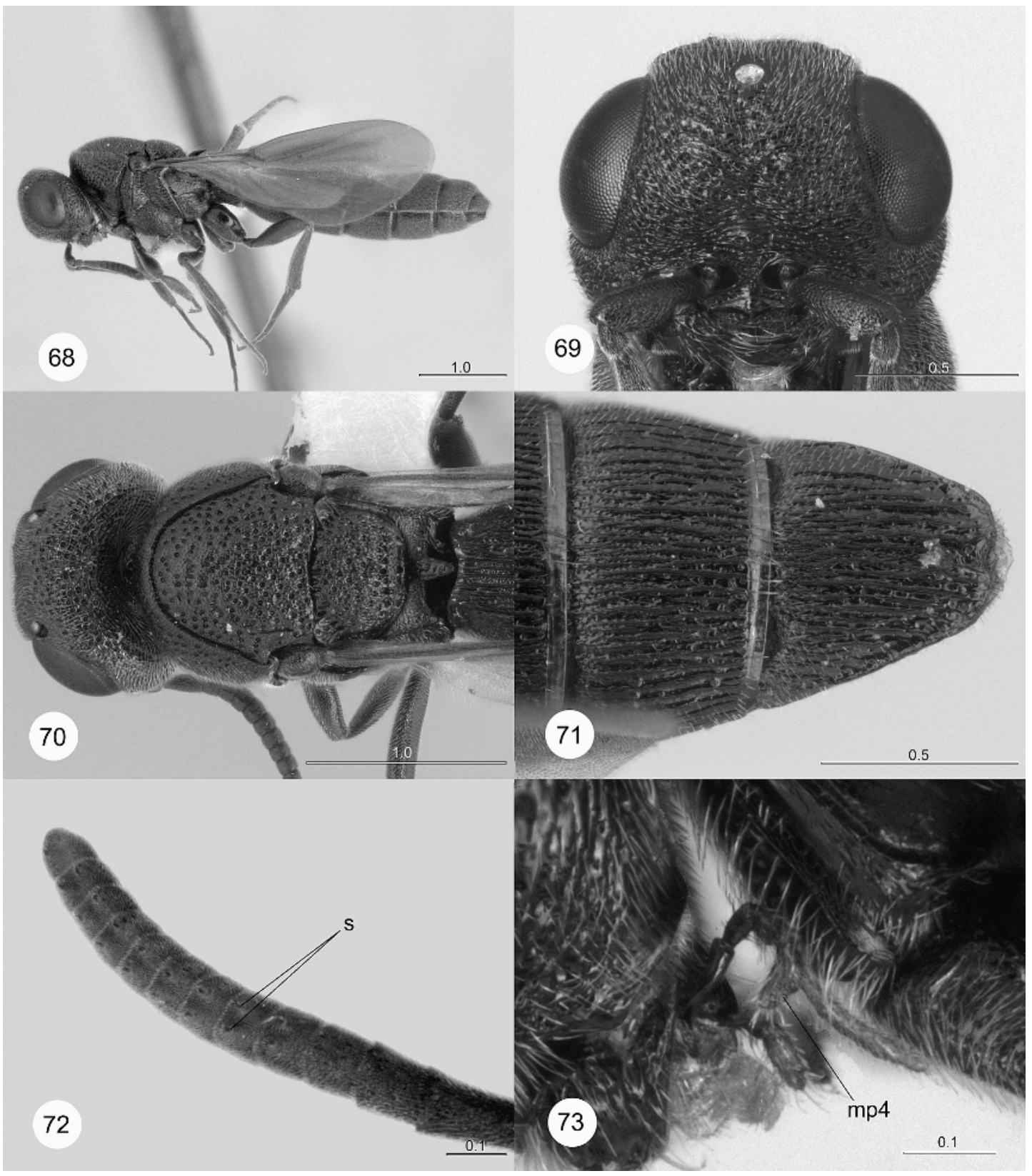

Figs. 68-73. Nixonia watshami, n.sp. 68. Lateral habitus (OSUC 146454). 69. Head, frontal view (OSUC 146454). 70. Head and mesosoma, dorsal view (OSUC 146454). 71. Apex of metasoma, dorsal view (OSUC 146456). 72. Antenna, ventral view (OSUC 146457). 73. Mouthparts, lateral view (OSUC 146457). $\mathrm{mp} 4$, maxillary palpomere $4 ; s$, paired multiporous basiconic sensilla. Scale in millimeters. 
area; sculpture of cheeks laterad of malar region with slight longitudinal orientation; mandible moderately long, bidentate, upper tooth only slightly longer than lower tooth, without dense basal tuft of setae; maxillary palpal segment 4 distinctly expanded, subtriangular (figs. 9, 73); A1 finely reticulate, greatest width in apical two-thirds of segment; length of A3 1.8 times length of A2.

Mesosoma (figs. 68, 70) as high as wide, length 1.3 times height in lateral view; pronotal shoulders rugose-punctate; lateral surface of pronotum with fine longitudinal rugulosity; netrion with weak longitudinal sculpture, deep punctures; mesoscutum rugose-punctate, without transverse elements in sculpture, shining; parapsidal lines absent; scutellum rugose-punctate, sculpture with fine longitudinal elements in posterior half; medial propodeal tooth strong, slightly longer than wide, rugulose, with slight emargination posteriorly; upper mesepisternum with strong longitudinal sculpture; fine foveolae separating mesepisternum and mesepimeron present in upper half of sclerite, absent below; lower mesepisternum finely reticulate-punctate; mesepimeral hook longitudinally keeled; tegula with granular microsculpture; apex of $\mathrm{R}_{1}$ in forewing touching costal margin; apex of forewing slightly surpassing apex of $\mathrm{T} 4$; $\mathrm{R}$ in hindwing with tracheate section long, nearly reaching hamuli; tibiae with only fine, semidecumbent spines on outer surface.

Metasoma (fig. 71) 2.9 times longer than greatest width; T1 distinctly wider than long; all terga longitudinally rugose; T6 with moderately large emargination medially, width of emargination greater than depth; base of T6 with anteromedial field of granulate microsculpture.

DiAgnosis: This is a rather small and unremarkable species of Nixonia. It seems to be most similar to $N$. pretiosa and may be distinguished by its uniformly dark color.

BIOLOGY: Egg parasitoid of Acanthoplus discoidalis (Walker) (Orthoptera: Tettigoniidae, Hetrodinae).

ETymology: Named in honor of Anthony Watsham, wonderful friend and great naturalist, who has dedicated his life to Zimbabwe.

Material Examined: Holotype female, BOTSWANA: Serowe, Farmer's Brigade,
III.1992, P. Forchammer, malaise trap, OSUC 146414, deposited in CNCI. Paratypes: BOTSWANA: Central Dist., Serowe, II.1990, P. Forchhammer, malaise trap, 1 male, CASENT 2042613; III.1990, 2 males, CASENT 2042615, CASENT 2042614; IV.1990, 2 males, CASENT 2042617, CASENT 2042616; V.1990, 1 male, CASENT 2042612. Serowe, Farmer's Brigade, II.1989, P. Forchhammer, malaise trap, 1 male, OSUC 149459; III.1986, malaise trap, 1 female, OSUC 146413; III.1989, malaise trap, 1 male, OSUC 149449; III.1993, malaise trap, 2 males, OSUC 146417, OSUC 146418; IV.1986, malaise trap, 1 male, OSUC 146416; 5-8.V.1994, malaise trap, 1 male, OSUC 146415; V.1987, 1 female, OSUC 146412; V.1989, malaise trap, 17 males, 1 female OSUC 149431, OSUC 149432, OSUC 149433, OSUC 149434, OSUC 149435, OSUC 149436, OSUC 149437, OSUC 149438, OSUC 149439, OSUC 149440, OSUC 149441, OSUC 149442, OSUC 149443, OSUC 149444, OSUC 149445, OSUC 149446, OSUC 149447, OSUC 149448; VI.1988, malaise trap, 3 males, OSUC 149451, OSUC 149452, OSUC 149453; VII.1988, malaise trap, 4 males, OSUC 149454, OSUC 149455, OSUC 149456, OSUC 149457; X.1988, malaise trap, 1 male, OSUC 149458. No locality data, reared ex eggs of Acanthoplus discoidalis, C 805, 2 males, 2 females, OSUC 149820, OSUC 149821, OSUC 149822, OSUC 149823. NAMIBIA: Ovambo, Omusati, 1997 (probably IV-VI.1997), from eggs of bush cricket Acanthoplus discoidalis, wasp emerged V.2000, 1 female, OSUC 146456. Gobabis, Farm Vendetta 202, Swart Nossob R., $21^{\circ} 55^{\prime} \mathrm{S}$ $18^{\circ} 11^{\prime} \mathrm{E}, 26-28 . X I .1996$, M. E. Irwin, E. I. Schlinger, E. Marais, malaise trap, 1 female, OSUC 146457. ZIMBABWE: Harare [recorded as Salisbury], IV.1982, A. Watsham, 1 male, OSUC 146452; V.1982, 2 males, OSUC 146453, OSUC 146454. Deposited in CASC, CNCI, OSUC, SANC, UCDC, USNM.

Comments: Armored bush crickets are pests of millet and sorghum in southern Africa (www.icrisat.org/satrends/01aug/1.htm). In this area of erratic rainfall, it is normal for some of the eggs to hatch not in the season immediately following oviposition, but one year later. Apparently, this is also true of its egg parasit- 


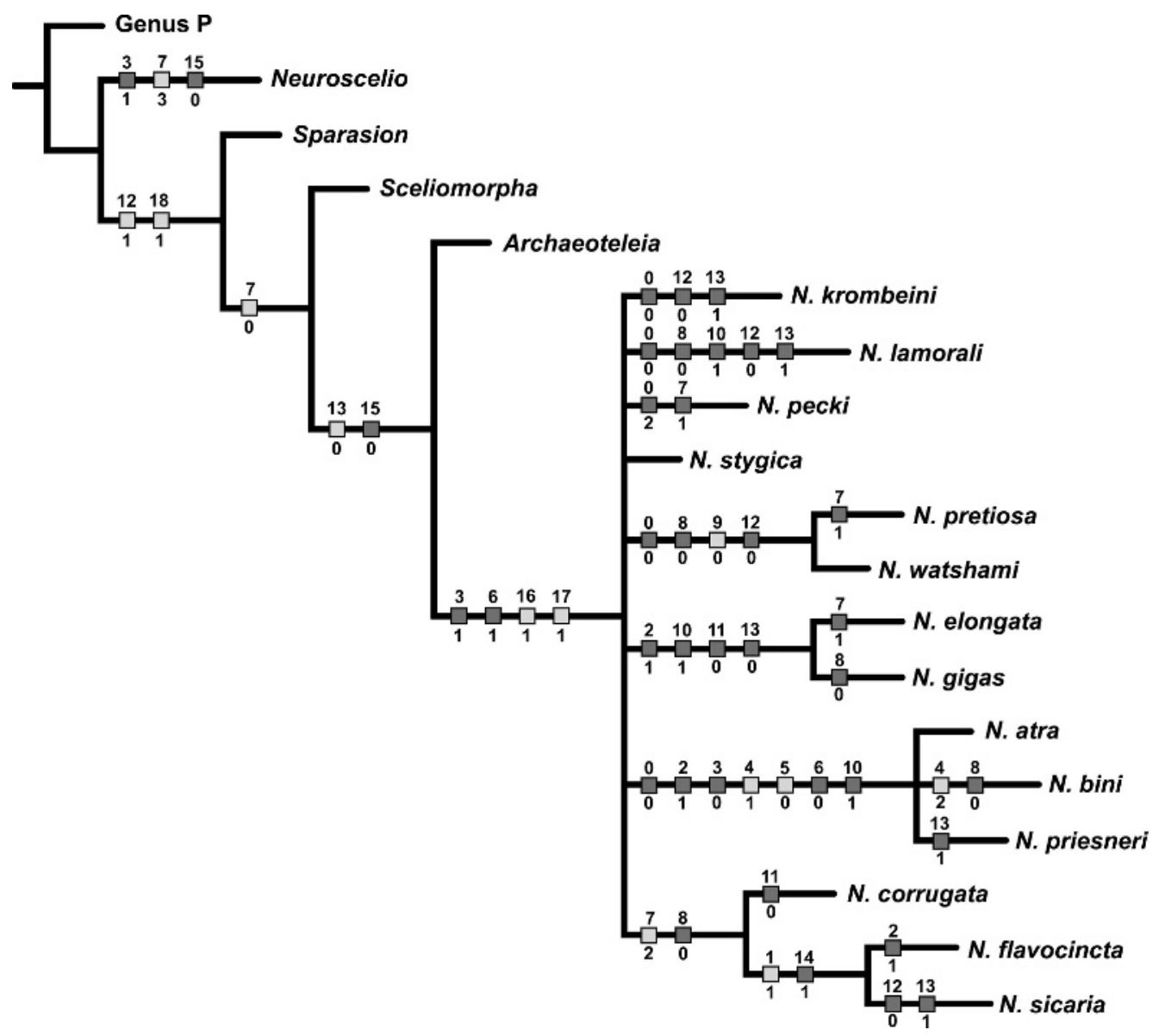

Fig. 74. Phylogenetic relationships among species of the genus Nixonia. Light-colored squares indicate nonhomoplasious apomorphic character-state changes; dark squares indicate homoplasious character-state changes. Numbers above squares are character numbers; numbers below squares are the corresponding character-state changes (see appendix 1 ). Statistics: length $=57$; consistency index $=45$; retention index $=59$.

oid. S. V. Green (personal commun.) reported "...the Acanthoplus eggs had lain dormant [in the laboratory] for several years, then I incubated them under moist conditions and had some hatching of Acanthoplus (no parasitoids detected at that time). Then I reincubated the unhatched Acanthoplus eggs a year later and this time got the single Nixonia, but no armored bush crickets."

\section{PHYLOGENY}

The relationships among species of Nixonia were investigated using WinClada (Nixon
2002) and Nona (Goloboff, 1999). The characters and states are described in appendix 1. Outgroups for the analysis were Genus P (a new taxon currently being described), Neuroscelio doddi Galloway, Austin and Masner, Archaeoteleia mellea Masner, and undescribed species of Sceliomorpha Ashmead and Sparasion Latreille. Together, these encompass the extant groups of scelionids retaining the 1-2-2 tibial spur formula. Analyses resulted in a suite of 39 equally parsimonious trees of length 49 (consistency index $=53$, retention index $=70$ ). The consensus tree from this suite (fig. 74: length 
57, CI 45, RI 59) identifies four clusters of species: the pair of $N$. pretiosa and $N$. watshami; the pair $N$. elongata and $N$. gigas; the three species $N$. atra, N. bini, and $N$. priesneri; and the three species $N$. corrugata, $N$. flavocincta, and $N$. sicaria.

The species pair $N$. pretiosa and $N$. watshami are extremely similar. The most striking difference is the unique red coloration of $N$. pretiosa. Nixonia watshami is one of the bestcollected species, particularly through the Malaise trapping effort of Forchhammer in Botswana. None of these specimens, collected through all seasons and over several years, has any indication of red coloration. The trio of $N$. atra, $N$. bini, and $N$. priesneri are all united by the structure of the mandibles and maxillary palpi. The trio of $N$. corrugata, $N$. flavocincta, and $N$. sicaria are best characterized by the length of the third antennomere, which is shorter than the second. In all other species in the genus the pedicel is longer than the basal flagellomere.

It is premature to attach any significant biogeographical interpretation to this phylogenetic hypothesis. The only Asian species, $N$. krombeini, appears as part of the basal polytomy for the genus. However, the data currently available do not allow for a clear resolution of relationships to suggest, e.g., a dichotomy between African and Asian species. We also believe that we still have much to learn about the distribution of individual species through additional sampling.

\section{ACKNOWLEDGMENTS}

We thank S. V. Green, P. Mviha, and J. Mitchell for biological observations on $N$. watshami; L. Musetti and J. Cora for database support; and S. Westby for the excellent line drawings. This material is based upon work supported in part by the National Science Foundation under grant No. DEB-0344034.

\section{REFERENCES}

Austin, A.D., and S.A. Field. 1997. The ovipositor system of scelionid and platygastrid wasps
(Hymenoptera: Platygastroidea): comparative morphology and phylogenetic implications. Invertebrate Taxonomy 11: 1-87.

Austin, A.D., N.F. Johnson, and M. Dowton. 2005. Systematics, evolution, and biology of scelionid and platygastrid wasps. Annual Review of Entomology 50: 553-582.

Bin, F. 1981. Definition of female antennal clava based on its plate sensilla in Hymenoptera Scelionidae Telenominae. Redia 64: 245-261.

Goloboff, P.A. 1999. Nona, version 2.0. Program and documentation. Tucumán, Argentina: Fundación e Instituto Miguel Lillo.

Johnson, N.F. 1992. Catalog of world Proctotrupoidea excluding Platygastridae. Memoirs of the American Entomological Institute No. 51, 825 pp.

Kozlov, M.A. 1970. [Supergeneric groupings of Proctotrupoidea (Hymenoptera).] Entomologicheskoye Obozreniye 49: 203-226.

Kozlov, M.A., and S.V. Kononova. 1990. [Scelioninae of the fauna of the USSR (Hymenoptera, Scelionidae, Scelioninae).] Leningrad: Nauka, 344 pp.

Masner, L. 1958. An interesting new genus of Scelionidae from S.W. Africa (Hymenoptera: Proctotrupoidea). Proceedings of the Royal Entomological Society of London (B) 27: 101-104.

Masner, L. 1965. The types of Proctotrupoidea (Hymenoptera) in the British Museum (Natural History) and in the Hope Department of Entomology, Oxford. Bulletin of the British Museum (Natural History), Entomology Supplement No. 1. 154 pp.

Masner, L. 1970. A new species of Nixonia Masner from Rhodesia. Proceedings of the Entomological Society of Washington 72: 90-93.

Masner, L. 1976. Revisionary notes and keys to world genera of Scelionidae (Hymenoptera: Proctotrupoidea). Memoirs of the Entomological Society of Canada 97: 1-87.

Masner, L., and L. Huggert. 1989. World review and keys to genera of the subfamily Inostemmatinae with reassignment of the taxa to the Platygastrinae and Sceliotrachelinae (Hymenoptera: Platygastridae). Memoirs of the Entomological Society of Canada 147: 1-214.

Nixon, K.C. 2002. Winclada ver. 1.00.08. Ithaca, NY: published by the author.

Otte, D., C.C. Eades, and P. Naskrecki. Orthoptera Species File Online. Version 2.2. Last accessed: 31 January, 2005. <http://osf2. orthoptera.org $>$. 


\section{APPENDIX 1}

The characters and their states are listed first. All characters were treated as nonadditive. The complete data matrix follows.

0 . Development of occipital carina: absent $=0$; low $=1$; massive $=2$.

1. IOS vs. EH: IOS wide (e.g., figs. 12, 13) = 0 ; IOS strongly narrowed (fig. 7) $=1$.

2. Apical margin of clypeus: convex $=0$; straight $=1$.

3. Mandible length: elongate $=0$; short $=1$.

4. Mandibular dentition: bidentate, teeth subequal in size $=0$; bidentate, upper tooth longer $=1$; unidentate $=2$; tridentate $=3$; bidentate, lower tooth longer $=4$.

5. Mandibular setation: with dense tuft of setae basally $=0$; without tuft $=1$.

6. Maxillary palpal segment 4: straight (fig. 8) $=0$; medially produced (fig. 9) $=1$.

7. Length of A3 vs. length of A2: much longer $(\geq 1.8 \times$, fig. 6$)=0$; slightly longer $(1.2-$ $1.3 \times$, fig. 5 ) $=1$; shorter (fig. 4$)=2$.

8. Scutellar sculpture: with longitudinal elements $=0$; without longitudinal elements $=1$.

9. Apex of propodeal tooth: excised $=0$; entire $=1$.

10. Apex of forewing $\mathrm{R}_{1}$ : close to costal margin $=0$; far from costal margin $=1$.

11. Length of forewing: not reaching $\mathrm{T} 5=0$; reaching to or beyond $\mathrm{T} 5=1$.

12. $\mathrm{R}$ in hindwing: nearly reaching hamuli $=0$; broadly separated from hamuli $=1$; complete, extending to hamuli $=2$.
13. Sculpture of T6: with longitudinal elements $=0$; without longitudinal elements $=1$.

14. Color of femur and tibia: reddish brown to black $=0$; yellow $=1$.

15. Insertion of radicle into scape: apically $=0$; subapically $=1$.

16. Mesepimeral hook: absent $=0$; present $=1$.

17. Arrangement of claval basiconic sensilla: in longitudinal pairs $=0$; in transverse pairs $=1$.

18. Mandibular teeth array: vertical $=0$; transverse $=1$.

\begin{tabular}{ll}
\hline \hline Genus P & $100041111-112101000$ \\
Archaeoteleia & $100001001-011010001$ \\
Sceliomorpha & $100001001-011111001$ \\
Sparasion & $100001011-011101001$ \\
Neuroscelio & $100131031-012100000$ \\
N. atra & 0010100011111000111 \\
N. bini & 0010200001111000111 \\
N. corrugata & 1001011201001000111 \\
N. elongata & 1011011111100000111 \\
N. flavocincta & 1111011201011010111 \\
N. gigas & 1011011001100000111 \\
N. krombeini & 2001011011010100111 \\
N. lamorali & 0001011001110100111 \\
$N$. pecki & 2001011111011000111 \\
N. pretiosa & 0001011100010000111 \\
$N$. priesneri & 0010100011111100111 \\
$N$. sicaria & 1101011201010110111 \\
$N$. stygica & 1001011011011000111 \\
N. watshami & 0001011000010000111 \\
\hline
\end{tabular}

Complete lists of all issues of the Novitates and the Bulletin are available at World Wide Web site http://library.amnh.org/pubs. Inquire about ordering printed copies via e-mail from scipubs@amnh.org or via standard mail from: American Museum of Natural History, Library-Scientific Publications, Central Park West at 79th St., New York, NY 10024. TEL: (212) 769-5545. FAX: (212) 769-5009. 